\title{
Hygric properties of porous building materials (VI): a round robin campaign
}

Chi Feng ${ }^{1, *}$, Ana Sofia Guimarães ${ }^{2}$, Nuno Ramos ${ }^{2}$, Lixin Sun ${ }^{3}$, Dariusz Gawin ${ }^{4}$, Piotr Konca ${ }^{4}$, Christopher Hall ${ }^{5}$, Jianhua Zhao ${ }^{6}$, Hauke Hirsch ${ }^{6}$, John Grunewald $^{6}$, Maria Fredriksson ${ }^{7}$, Kurt

Kielsgaard Hansen ${ }^{8}$, Zbyšek Pavlík ${ }^{9}$, Andrea Hamilton ${ }^{10}$, Hans Janssen ${ }^{1}$

1. KU Leuven, Department of Civil Engineering, Building Physics and Sustainable Design, 3001 Leuven, Belgium

2. CONSTRUCT-LFC, Faculty of Engineering, University of Porto, 4200-465 Porto, Portugal

3. China Academy of Building Research, Institute of Building Environment and Energy, 100013 Beijing, China

4. Łódź University of Technology, Department of Building Physics and Building Materials, 90-924 Łódź, Poland

5. School of Engineering, University of Edinburgh, EH9 3JL Edinburgh, UK

6. Technische Universität Dresden, Institute of Building Climatology, 01069 Dresden, Germany

7. Lund University, Department of Building and Environmental Technology, SE-221 00 Lund, Sweden

8. Technical University of Denmark, Department of Civil Engineering, Materials and Durability Section, 2800 Kgs. Lyngby, Denmark

9. Czech Technical University in Prague, Faculty of Civil Engineering, Department of Materials Engineering and Chemistry, 16629

Prague, Czech Republic

10. Department of Civil and Environmental Engineering, University of Strathclyde, Glasgow G1 1XJ, UK

\begin{abstract}
Hygric properties of porous building materials are important for hygrothermal analysis. Their experimental determination is however not always reliable, shown by the discrepant results from different laboratories on the same materials. In this study, a recent round robin campaign initiated by KU Leuven (Belgium) and participated in by eight institutes from different countries is reported. Ceramic brick was selected as the target material. The bulk density and open porosity from vacuum saturation tests, the capillary absorption coefficient and capillary moisture content from capillary absorption tests, and the vapor permeability from cup tests were measured. Results were analyzed statistically and compared with a previous round robin project, EC HAMSTAD. The reproducibility errors for determining the capillary absorption coefficient were noticeably reduced when compared with the EC HAMSTAD project, and the different laboratories in the present study obtained similar results from vacuum saturation tests and capillary absorption tests without a common protocol. For cup tests, large inter-laboratory discrepancies still exist. However, with a stringent common protocol different laboratories achieved consistent results. For all properties a common protocol did not change the average results of all laboratories.
\end{abstract}

Keywords: porous building material, hygric property, vacuum saturation, capillary absorption, vapor diffusion, round robin

\section{Introduction}

\subsection{Background}

Hygrothermal simulations are valuable for properly designing new buildings and renovating existing ones [1-3]. The built environment can also be optimally understood, controlled and improved with the assistance of hygrothermal simulations [4-6]. To reach these goals, hygrothermal simulations of buildings or the built environment must be performed reliably. Studies show that different 
Postprint: Feng C, et al. 2020. Hygric properties of porous building materials (VI): a round robin campaign. Building and Environment, 2020;185:107242.

hygrothermal models are mathematically similar or even equivalent, and that they can provide similar results, as long as two central factors - material properties and boundary conditions - are kept the same $[7,8]$. It is therefore important to determine material properties as accurately as possible.

The material properties involved in hygrothermal simulations can be generally classified as thermal properties (e.g. thermal conductivity) or hygric properties (e.g. vapor permeability). One method for their determination is via modeling. For instance, pore-structure-based models can be used to predict thermal conductivity [9] or moisture storage and transport properties (e.g. moisture retention curve and moisture permeability [10]). These pore-structure-based methods are still under development however, and measurements hence play the dominant role at present.

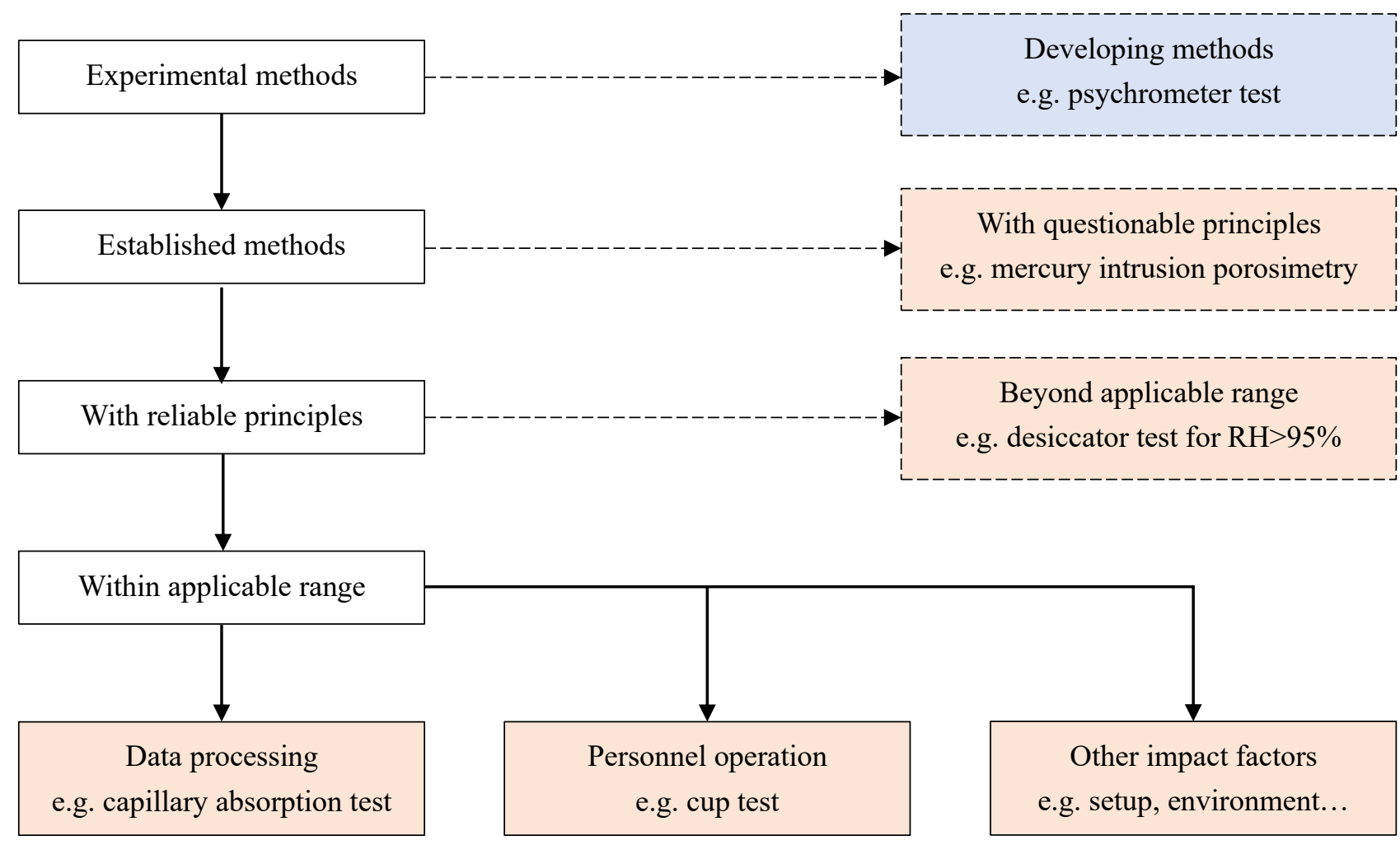

$$
\text { Capability issue Dependability issue }
$$

Fig.1 Challenges of measuring hygric properties of porous building materials

In general, measurements on the hygrothermal properties of porous building materials are physically straightforward, contributing to their worldwide application. For decades, experimental protocols for measuring thermal properties have been developed progressively. Numerous international, regional and national standards are available (e.g. the ISO 8301 and ASTM C518 standards [11, 12]) to prescribe the detailed operational procedures. The results are also relatively reliable. However, measurements on hygric properties still face capability and dependability issues, as illustrated in Fig.1. The capability issues refer to the fact that for some hygrothermal properties in the full humidity range their test methods are not yet fully established. For example, there are methods to measure adsorption moisture retention curves in the over-hygroscopic range [13-15], but these have not been standardized yet. The dependability issues, on the other hand, indicate that the established methods can still fail to produce trustworthy results. One possible cause is that the fundamental principles of some established 
Postprint: Feng C, et al. 2020. Hygric properties of porous building materials (VI): a round robin campaign. Building and Environment, 2020;185:107242.

doi: https://doi.org/10.1016/j.buildenv.2020.107242

methods might be questionable. For instance, mercury intrusion porosimetry [16] is the most common approach to determine the pore volume distribution of porous materials. Its results can be transformed into the moisture retention curve for desorption. However, doubts have been raised on its fundamental principles, such as the contact angle between mercury and the solid matrix [17], as well as the impact of the ink bottle effect [18]. Consequently, the results from mercury intrusion porosimetry should be treated carefully. Even if the basic principle of a test method is sound, it can still suffer from great uncertainties beyond its applicable range. For example, the desiccator test [19] is one of the most widely adopted techniques for measuring sorption isotherms in the hygroscopic range. However, saturated salt solutions are not completely reliable for RH levels above $95 \%$. Therefore, in this high humidity range the results from desiccator tests show significant scatter [20]. In addition, many factors - such as the data processing method [21], the personnel operation [22], etc. - can lead to uncertainties. A powerful method to investigate these uncertainties is to launch round robin campaigns, where different laboratories perform the same test on the same material. Unfortunately, almost all reported round robin campaigns show large deviations between different participants, requiring further studies.

\subsection{Round robin campaigns in brief}

In the past decades, there have been many round robin campaigns on measured hygric properties of porous building materials. Table 1 summarizes some of the most representative projects.

Table 1 Representative round robin campaigns for measuring the hygric properties of porous building materials

\begin{tabular}{ccccc}
\hline Project & $\begin{array}{c}\text { Year of } \\
\text { completion }\end{array}$ & $\begin{array}{c}\text { Number of } \\
\text { participants }\end{array}$ & Target materials & Measured properties \\
\hline CEC EUR 14394 EN [23] & 1993 & 13 & XPS, particle board & Vapor permeability \\
\hline Nordtest 1267-96 [24] & 1998 & 4 & Sandstone & Bulk density, open porosity, moisture retention \\
\hline Nordtest 1529-01 [25] & 2003 & 6 & $\begin{array}{c}\text { Hard wood fibre board, } \\
\text { underlay for roofing, } \\
\text { damp-proof course }\end{array}$ & Vapor permeability \\
EC HAMSTAD [26] & 2003 & 6 & $\begin{array}{c}\text { Calcium silicate, } \\
\text { aerated concrete, } \\
\text { ceramic brick }\end{array}$ & Bulk density, open porosity, capillary absorption \\
coefficient, capillary moisture content, vapor
\end{tabular}

Of all these round robin campaigns, the EC HAMSTAD project is one of the most representative examples. It involved three different porous building materials with "strong capillarity + strong hygroscopicity" (calcium silicate), "weak capillarity + strong hygroscopicity" (autoclaved aerated concrete) and "strong capillarity + weak hygroscopicity" (ceramic brick), representing a wide range of porous building materials. The set of measured hygric properties was also extensive, covering storage and transport properties in both the hygroscopic and the over-hygroscopic ranges, following general guidelines. Consequently, in the following analysis we use the results from the EC HAMSTAD project for comparison.

Some results from the EC HAMSTAD project for ceramic brick are illustrated in Fig. 2-4, with the error bars showing standard deviations for duplicate samples. These results include the bulk density $\left(\rho_{\text {bulk }}, \mathrm{kg} \cdot \mathrm{m}^{-3}\right)$ and open porosity $(\phi)$ from the vacuum saturation test, the capillary absorption coefficient $\left(A_{\text {cap }}, \mathrm{kg} \cdot \mathrm{m}^{-2} \mathrm{~s}^{-0.5}\right)$ and capillary moisture content $\left(w_{\text {cap }}, \mathrm{kg} \cdot \mathrm{m}^{-3}\right)$ from the capillary absorption 
Postprint: Feng C, et al. 2020. Hygric properties of porous building materials (VI): a round robin campaign. Building and Environment, 2020;185:107242.

doi: https://doi.org/10.1016/j.buildenv.2020.107242

test, as well as the vapor permeability (expressed as the vapor diffusion resistance factor $\mu$ ) from the cup test. All these test methods are well established and used within their application ranges. Two tendencies can be clearly identified. Firstly, the discrepancies between different laboratories are often much greater than the uncertainties within respective laboratories. Consequently, this restricts us to the

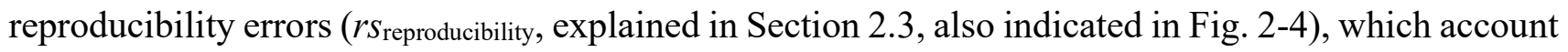
for the inter-laboratory differences. Secondly, the reproducibility errors for the moisture transport properties (such as $A_{\text {cap }}$ ) are in most cases greater than those for the moisture storage properties (such as $\left.w_{\text {cap }}\right)$.

In fact, these two tendencies observed in the EC HAMSTAD project are prevalent in all round robin campaigns. Motivated by these phenomena, some in-depth studies have been conducted for a better insight into and control of potential error sources. For example, repeatability and reproducibility analysis proves that neither the material inhomogeneity nor the experimental errors rooted in the methodologies themselves play a dominant role in the conspicuous inter-laboratory discrepancies [28]. Furthermore, time and personnel in the same lab do not lead to large errors, as long as protocols remain unchanged [22]. As a result, the experimental procedure, environmental control and the data processing appear to be the most responsible.

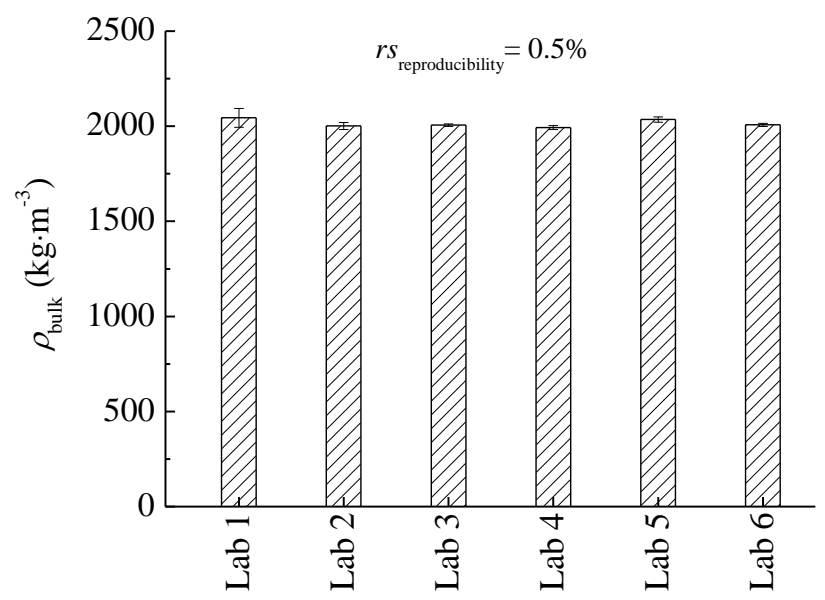

a) The bulk density

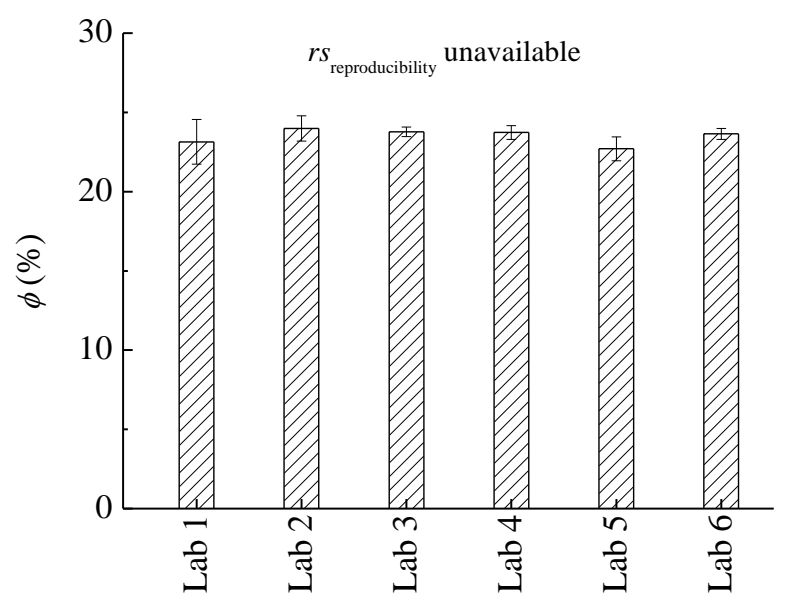

b) The open porosity

Fig. 2 Results of vacuum saturation tests for ceramic brick (from the EC HAMSTAD project [26])

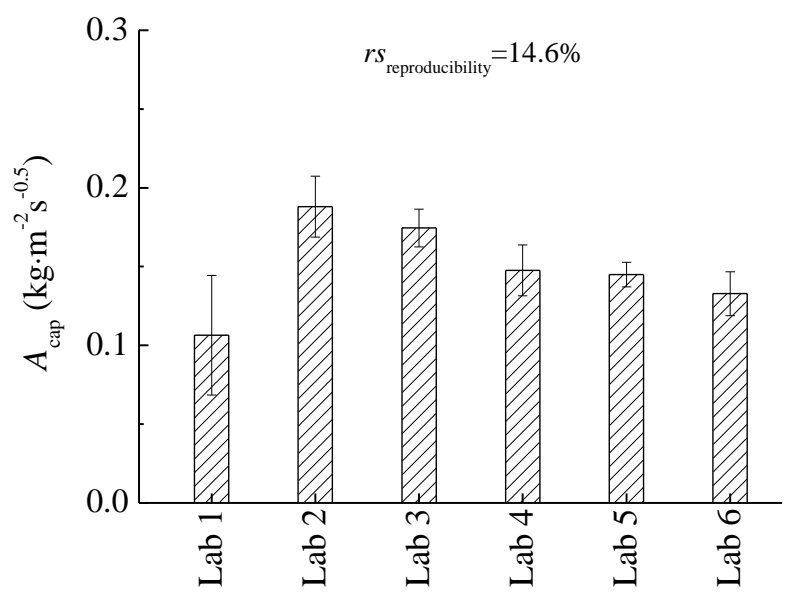

a) The capillary absorption coefficient

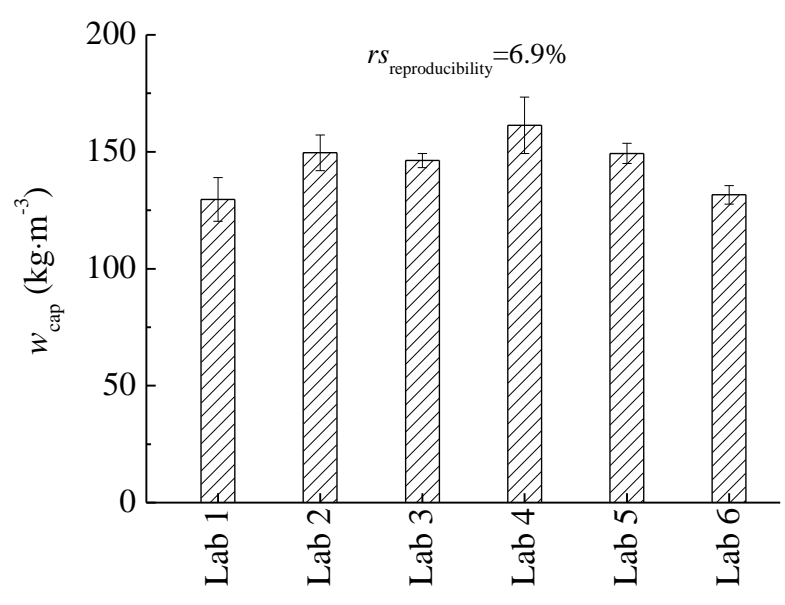

b) The capillary moisture content

Fig. 3 Results of capillary absorption tests for ceramic brick (from the EC HAMSTAD project [26]) 


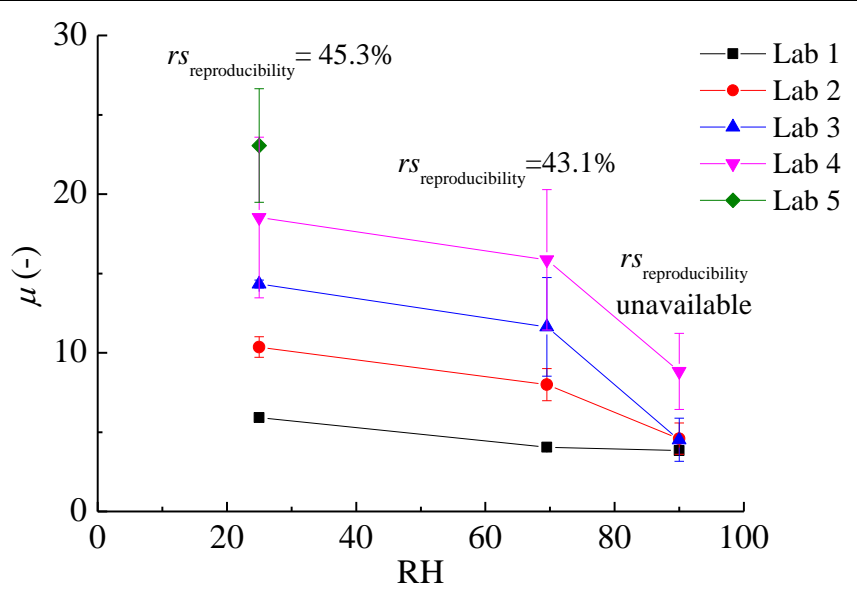

Fig. 4 Results of cup tests for ceramic brick (from EC HAMSTAD project [26])

\subsection{Objectives}

As many years have passed since the completion of the above-mentioned round robin campaigns, a new small-scale round robin campaign was initiated by KU Leuven (Belgium), to gain fresh input to quantify the consistency of experimental results from different laboratories, to locate sources of discrepancies, and to identify potential improvements in different laboratories. This campaign was planned at the end of 2017 and formally started in early 2018. Besides KU Leuven as the project coordinator, eight other institutes contributed to this campaign by measuring hygric properties: University of Porto (Portugal), China Academy of Building Research (P.R. China), Łódź University of Technology (Poland), University of Edinburgh (United Kingdom), Technical University of Dresden (Germany), Lund University (Sweden), Technical University of Denmark (Denmark) and Czech Technical University in Prague (Czech Republic). In addition, the X-ray diffraction (XRD) data were analyzed by University of Strathclyde (United Kingdom) for extra information. It should be noted that there was no direct funding for this campaign, so all participants were voluntarily involved and financially self-supported.

In the following sections, we first introduce the material and the methods used in this round robin campaign. Next, the experimental results from the participating laboratories are presented along with statistical analysis and comparison with the EC HAMSTAD project. After that, the conclusions from this study are drawn.

\section{Material and methods}

In this section, we first present the target material used for this round robin campaign. After that, the experimental arrangement and test methods are explained. Finally, statistical analysis methods are introduced.

\subsection{Material}

Given that this round robin campaign was unfunded, only a single target material was used: the Robusta Vandersanden ceramic brick [29]. It has a dark brown color and a raw dimension of $21 \mathrm{~cm} \times 10 \mathrm{~cm} \times 5 \mathrm{~cm}$. This brick does not go through carbonation, hydration or any other noticeable chemical change during the test period. Its mineral composition obtained by quantitative XRD is illustrated in Fig. 5. The crystalline minerals present are quartz (41.3\%), Ca-rich plagioclase feldspar (anorthite) (19.7\%), K-feldspar (sanidine) (2.7\%), hematite (4.1\%) and diopside (7.8\%). The estimated silica glass content is $24.4 \%$ using the PONKCS method [30]. The mineral assemblage is typical of a 
Postprint: Feng C, et al. 2020. Hygric properties of porous building materials (VI): a round robin campaign. Building and Environment, 2020;185:107242.

doi: https://doi.org/10.1016/j.buildenv.2020.107242

modern production brick with considerable calcium content, and with hematite and diopside as highdensity components. From the crystallographic mineral densities and the estimated density of the glassy phase [31], we estimate a solid density for this brick ceramic of $2740-2775 \mathrm{~kg} \cdot \mathrm{m}^{-3}$. Fig. 6 illustrates the pore volume distribution of this brick obtained by the mercury intrusion porosimetry. Based on its pore size, we can expect the brick to be strong in capillarity and weak in hygroscopicity.

For this round robin campaign, raw bricks from the same batch were randomly selected and distributed by KU Leuven to all other participants, to minimize the impact of material inhomogeneity.

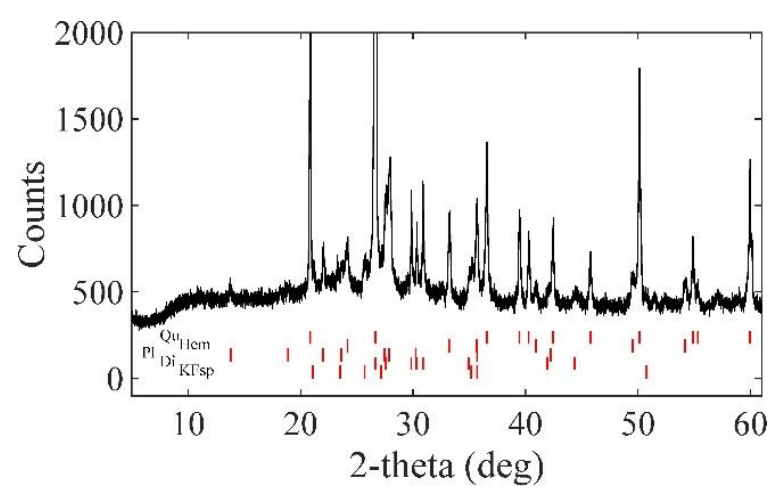

Fig. 5 The mineral phases of the target brick

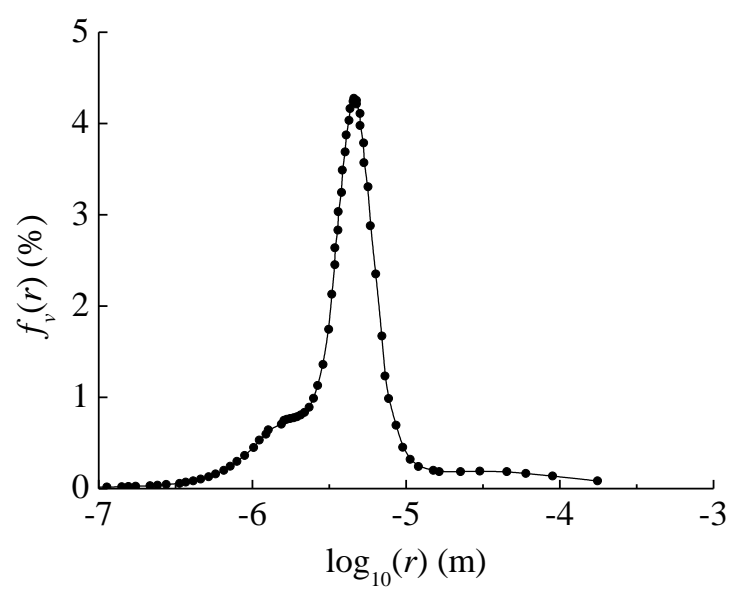

Fig. 6 The pore volume distribution of the target brick

\subsection{Test methods}

This round robin campaign focuses on established methods for measuring the hygric properties of porous building materials. The vacuum saturation test was executed for bulk density and open porosity, the capillary absorption test was performed for capillary absorption coefficient and capillary moisture content, and the cup test was carried out for vapor permeability. As the target brick is weak in hygroscopicity, the determination of hygroscopic sorption isotherms was not included. Moreover, because the pressure plate setup was not available in all participating laboratories, the moisture retention curve was not measured.

Two separate rounds of experiments were performed in the campaign. In the $1^{\text {st }}$ round, all participants carried out the tests according to their respective experimental protocols used in their own laboratories. Here, no instructions regarding sample size, relative humidity levels to include in the cup test, etc. were given. For the $2^{\text {nd }}$ round, a strict and detailed common protocol was prescribed for each test. The latter was based on standards ASTM C1585, ASTM C1794, ASTM E96, ISO 12572 and ISO 15148 [32-36], as well as on previous studies [28, 37-39]. Below, some key information on the common protocols for the $2^{\text {nd }}$ round is given, while full descriptions are provided in Appendix A.

\subsubsection{General requirements}

The ambient temperature for all measurements should be maintained within $20-25^{\circ} \mathrm{C}$, with a fluctuation smaller than $\pm 1^{\circ} \mathrm{C}$. The surface $0.5-1 \mathrm{~cm}$ of raw bricks should be removed, and at least 4 duplicates are required for each test. Sample dimensions should be measured with calipers reading to $0.01 \mathrm{~mm}$. Samples should be dried in a ventilated oven at $70^{\circ} \mathrm{C}$ for at least 7 days.

\subsubsection{Vacuum saturation test}

The air pressure in the vacuum container should stay below $3000 \mathrm{~Pa}$ for at least $4 \mathrm{~h}$ to completely evacuate the air inside samples. While filling water, the water level should rise at a speed of around 5 
Postprint: Feng C, et al. 2020. Hygric properties of porous building materials (VI): a round robin campaign. Building and Environment, 2020;185:107242.

doi: https://doi.org/10.1016/j.buildenv.2020.107242

$\mathrm{cm} \cdot \mathrm{h}^{-1}$ (or slower) until all samples are completely underwater. After returning the air pressure in the container to atmospheric pressure, samples should be kept underwater for at least $24 \mathrm{~h}$ before weighing.

\subsubsection{Capillary absorption test}

The top and lateral sides of the sample should be wrapped with either plastic film or aluminum foil, with 1-2 small holes at the top to allow air evacuation. The bottom $1 \mathrm{~cm}$ of the lateral sides should be left unwrapped to avoid capillary uptake between the sample and the wrap. The water in the basin should stay 3-5 mm above the sample bottom. The capillary absorption coefficient should be derived according to the one-tangent method [21], and the capillary moisture content should be calculated according to the Appendix.

\subsubsection{Cup test}

The sample should be sealed on the opening of the diffusion cup with epoxy, paraffin or other vaportight methods. While sealing, the penetration of the sealant into the sample should be minimized. The air layer resistance inside the cup should be corrected, and the surface transfer resistance above the sample should be minimized by increasing the air velocity to at least $1 \mathrm{~m} \cdot \mathrm{s}^{-1}$. While processing the data, the sample's masked edge (if any) should be corrected according to the ISO 12572 standard [35].

\subsection{Statistical analysis methods}

To quantitatively evaluate the experimental results, two statistical methods were employed. First, the t-test was used to compare the overall results from the $1^{\text {st }}$ and the $2^{\text {nd }}$ rounds of experiments. Due to the availability of time, personnel and experimental facilities, not all laboratories finished all three tests for the five properties in both rounds. As a result, the paired t-test is not applicable and hence the independent t-test was utilized instead [40]. Specifically, for any given property, the average value of each lab was calculated first. Next, all the lab-averaged values were classified into two groups for the $1^{\text {st }}$ and the $2^{\text {nd }}$ rounds, respectively. After that, the independent t-test on these two groups was performed, verifying whether the lab-averaged results of the two rounds of experiments are statistically different.

The main aim of the independent t-test is to compare the averages of the $1^{\text {st }}$ round and the $2^{\text {nd }}$ results of all laboratories. However, it cannot clarify the major concern of this study - the discrepancies between different laboratories - in a thorough way. For this reason, we also adopted the statistical indicators proposed by the ISO 5725 standard [41], which have also been applied in other studies [22, 28]:

a) The material error ( $\left.r s_{\text {material }}\right)$ : representing the errors (relative standard deviations) caused by a material's inhomogeneity;

b) The repeatability error $\left(r s_{\text {repeatability }}\right)$ : representing the errors in repeating the measurements on the same samples when all relevant factors (operator, equipment, calibration, etc.) remain unchanged;

c) The reproducibility error ( $\left.r s_{\text {reproducibility }}\right)$ : representing the errors of replicate measurements in different laboratories.

In general, $r s_{\text {material }}$ can never be eliminated, since no material is perfectly homogeneous. Meanwhile, $r s_{\text {repeatability }}$ reflects the smallest random error inherent to a test method (when $r s_{\text {material }}$ is not considered) and hence indicates the lower limit of experimental accuracy. If any error is smaller than or similar to

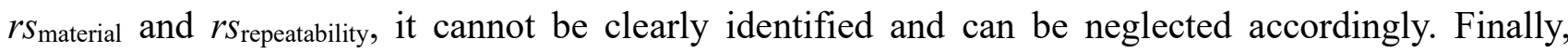

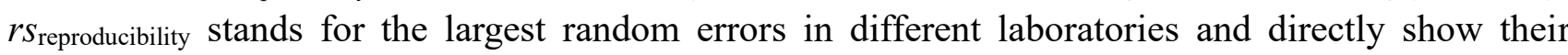
discrepancies. Obviously, the smaller $r s_{\text {reproducibility }}$ is, the more similar results different laboratories can achieve.

The calculation of $r s_{\text {material, }}, r s_{\text {repeatability }}$ and $r s_{\text {reproducibility }}$ is intricate: details have been elaborated in 
Postprint: Feng C, et al. 2020. Hygric properties of porous building materials (VI): a round robin campaign. Building and Environment, 2020;185:107242.

doi: https://doi.org/10.1016/j.buildenv.2020.107242

ref. $[28,41]$, and we do not repeat them in this paper. It should be noted that due to the calculation complexity, $r s_{\text {reproducibility }}$ is not always available. This mainly happens to extreme cases when the between-lab errors are comparable to the within-lab errors (such as the open porosity in the EC HAMSTAD project, Fig. 2 b), so that the differences between different laboratories cannot be distinguished. It is also worth mentioning that $r s_{\text {material }}$ and $r s_{\text {repeatability }}$ obtained in different laboratories can vary slightly. However, since they are normally much smaller than $r s_{\text {reproducibility, their small }}$ variances should only have a limited impact on the general analysis. In this round robin campaign, we

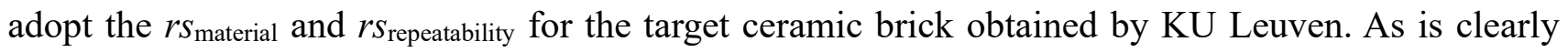
reflected in Table 2, these two errors are typically smaller than 10\% (cup tests), 5\% (capillary absorption tests) and $1 \%$ (vacuum saturation tests).

Table 2 The material and repeatability errors of the target ceramic brick

\begin{tabular}{cccccccc}
\hline Test & \multicolumn{2}{c}{ Vacuum saturation } & \multicolumn{2}{c}{ Capillary absorption } & \multicolumn{3}{c}{ Cup test } \\
Property & $\rho_{\text {bulk }}$ & $\phi$ & $A_{\text {cap }}$ & $w_{\text {cap }}$ & $\mu_{1}$ & $\mu_{2}$ & $\mu_{3}$ \\
\hline$r s_{\text {material }}(\%)$ & 0.13 & 0.45 & 2.76 & 3.39 & 8.36 & 8.79 & 6.84 \\
$r s_{\text {repeatability }}(\%)$ & 0.17 & 0.44 & 2.02 & 0.41 & 2.73 & 0.55 & 1.89 \\
\hline
\end{tabular}

* The RH settings for $\mu_{1}, \mu_{2}$ and $\mu_{3}$ are $11.3 \%-53.5 \%, 53.5 \%-84.7 \%$ and $84.7 \%-97.4 \%$, respectively.

\section{Results and discussion}

In this section, we report the results obtained from the vacuum saturation test, the capillary absorption test and the cup test (detailed values are reported in Appendix B). Analysis of and comparisons between the $1^{\text {st }}$ and the $2^{\text {nd }}$ rounds of experiments are made. Results from the EC HAMSTAD project are also referred to. It must be emphasized that the lab numbers in this section are denoted as A-I, without any link to the affiliation numbers for the co-authors. It should also be remarked that the brick used in this campaign differs from the EC HAMSTAD brick in the homogeneity and investigated properties. However, these differences mainly affect the material errors to a limited degree, and a comparison of reproducibility errors is still valid. Lastly, it is worth mentioning that the common protocols were derived from the routines of Lab A. In other words, Lab A was following the common protocols all the time. For this reason, the same set of data from Lab A suits both rounds.

All tests were carried out at $20-25^{\circ} \mathrm{C}$. In this limited temperature range the capillary absorption coefficient can vary by about $5 \%[37,39,42]$, while all other investigated properties can be considered as temperature-independent [37]. Consequently, equation (1) derived from ref. [37] was used to correct the capillary absorption coefficients from different laboratories to values at $20^{\circ} \mathrm{C}$ for better comparison. Note that Lab I did not report the temperature in the $1^{\text {st }}$ round for the capillary absorption test, so their results remained uncorrected.

$$
A_{\text {cap }}\left(20^{\circ} \mathrm{C}\right)=\frac{A_{\text {cap }}(T)}{0.0112(T-273.15)+0.7756}
$$

where $T$ is the absolute temperature, $\mathrm{K}$.

\subsection{Vacuum saturation tests}

Fig. 7 illustrates the bulk density and open porosity obtained from the vacuum saturation test. A first glance shows that for both properties the discrepancies between the different laboratories are not significant. However, the open porosity reported by Lab B is noticeably lower in both rounds of 
Postprint: Feng C, et al. 2020. Hygric properties of porous building materials (VI): a round robin campaign. Building and Environment, 2020;185:107242.

doi: https://doi.org/10.1016/j.buildenv.2020.107242

experiments. After a thorough check, the experimental procedure has been identified as the main reason: contrary to other laboratories who first evacuated the air in the vacuum container and then filled in water, Lab B operated in the reverse order. As a result, some air was probably retained in the sample, leading to the underestimated open porosity. Moreover, Lab F surprisingly provided an even smaller open porosity than Lab B, which is problematic. There is no clear explanation for this underestimation, and the insufficient air evacuation before water filling may also be the most possible reason.

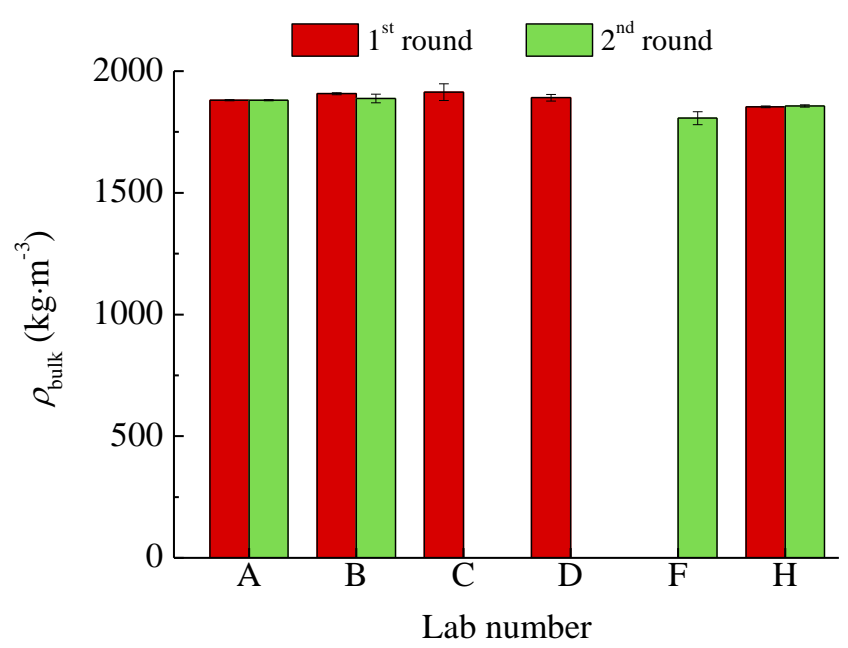

a) The bulk density

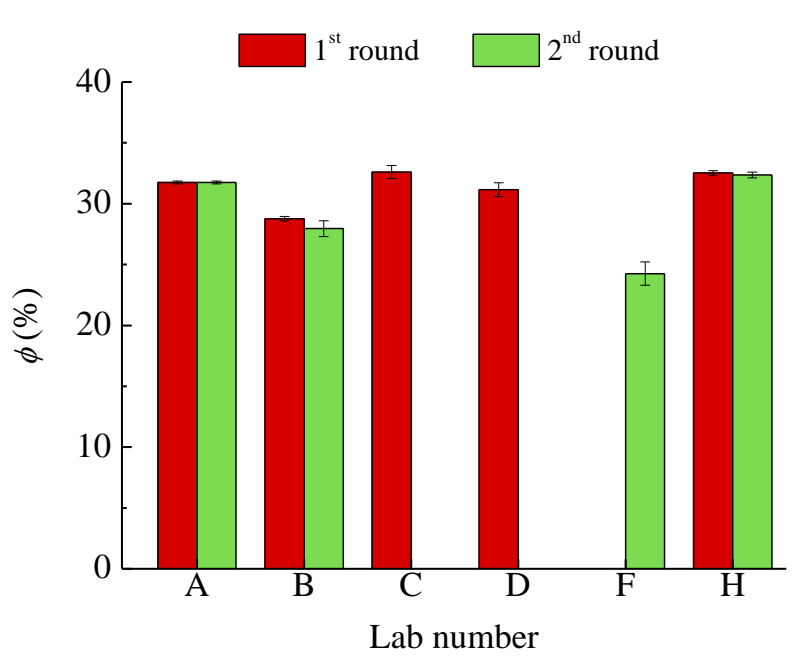

b) The open porosity

Fig. 7 Results of the vacuum saturation test

With bulk density and open porosity, the matrix density could be easily derived for a further check [43, 44]. As summarized in Table 3, the matrix densities from most laboratories are similar. Nevertheless, Lab $\mathrm{F}$ in the $2^{\text {nd }}$ round gave an abnormally low value, confirming the existence of mistakes during the test. However, the determination of bulk volume by Archimedes buoyancy does not require complete air evacuation. Thus the bulk densities obtained by Lab B in both rounds and Lab $\mathrm{F}$ in the $2^{\text {nd }}$ round were still reasonable. The matrix density provides a quality check on the Archimedes porosity. For this ceramic brick, the mean matrix density calculated from the measured bulk density and measured porosity is 2753 and $2706 \mathrm{~kg} \cdot \mathrm{m}^{-3}$ for the $1^{\text {st }}$ round and the $2^{\text {nd }}$ round, respectively. These values are in acceptable agreement with the estimation from the mineralogical composition by XRD (Section 2.1) and place this brick at the high end of the known solid density range of ceramic bricks, broadly $2600-2750 \mathrm{~kg} \cdot \mathrm{m}^{-3}$ [43]. However, several laboratories reported values either higher or lower, which cannot be reconciled with the known composition. This confirms the value of using the matrix density as a quality check [44].

Table 3 The matrix density $\left(\mathrm{kg} \cdot \mathrm{m}^{-3}\right)$ from different laboratories

\begin{tabular}{ccccccc}
\hline Lab No. & A & B & C & D & F & H \\
\hline $1^{\text {st }}$ round & 2754 & 2677 & 2839 & 2746 & - & 2750 \\
$2^{\text {nd }}$ round & 2754 & 2620 & - & - & 2385 & 2744 \\
\hline
\end{tabular}

To have a quantitative view on the discrepancies between different laboratories in this round robin campaign, we refer to the statistical parameters described in Section 2.3. It should be noted that the 
Postprint: Feng C, et al. 2020. Hygric properties of porous building materials (VI): a round robin campaign. Building and Environment, 2020;185:107242.

doi: https://doi.org/10.1016/j.buildenv.2020.107242

open porosity from Lab B was not included for error calculations, as its problematic procedure produces unrepresentative results. The deviating open porosity from Lab $\mathrm{F}$ in the $2^{\text {nd }}$ round was also excluded. To start with, the independent t-tests were performed to compare the lab-averaged results in the $1^{\text {st }}$ and the $2^{\text {nd }}$ rounds of experiments for all laboratories. The calculated p-values are 0.164 and 0.947 for the bulk density and the open porosity respectively, indicating that the average values of bulk density and open porosity were not statistically different in both rounds. In other words, the common protocol for the vacuum saturation imposed in the $2^{\text {nd }}$ round of experiments did not change the average results of all laboratories significantly.

Furthermore, reproducibility errors were evaluated to check whether the common protocol reduced the discrepancies between different laboratories. The calculated results are illustrated in Fig.8, in comparison with the EC HAMSTAD project. Clearly, in terms of the variations between different laboratories, the determination of the bulk density and the open porosity is very satisfactory in both rounds. The inter-laboratory discrepancies stay within $2 \%$, albeit slightly greater than those in the EC HAMSTAD project. It should be noted that for the bulk density the reproducibility errors in the $2^{\text {nd }}$ round are slightly greater than those in the $1^{\text {st }}$ round. This, however, does not demonstrate that a common protocol exerted a negative impact in this case, because fewer laboratories were involved in the $2^{\text {nd }}$ round, leading to greater statistical uncertainties. Anyway, it can be concluded that the vacuum saturation test is highly reliable and a common protocol is not indispensable, as long as the experimental procedure is correct. This may be attributed to the fact that the vacuum saturation test is very simple in both operational procedure and data processing, without strong impact factors. It is also possible that the respective protocols adopted by different laboratories were the same as or modified from a standard, with similar and adequate details.

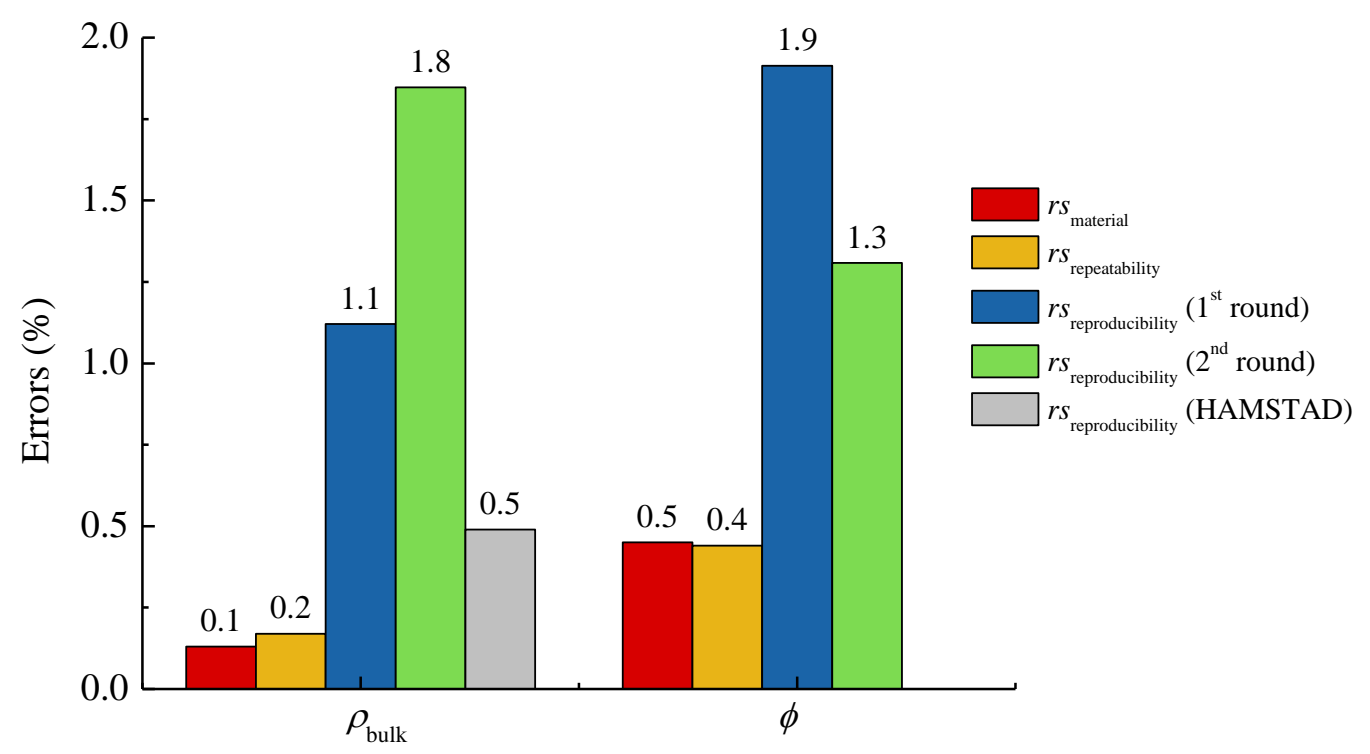

Fig. 8 Experimental errors of the round robin vacuum saturation test

\subsection{Capillary absorption tests}

Fig. 9 illustrates the capillary absorption coefficient and capillary moisture content obtained from the capillary absorption test. Generally speaking, the results of all laboratories stay reasonably similar. The calculated $\mathrm{p}$-values from the independent t-tests comparing the overall results of two rounds are 0.154 and 0.906 for the capillary absorption coefficient and the capillary moisture content, respectively. Similar to the vacuum saturation test, the capillary absorption test hence also showed no statistical 
Postprint: Feng C, et al. 2020. Hygric properties of porous building materials (VI): a round robin campaign. Building and Environment, 2020;185:107242.

doi: https://doi.org/10.1016/j.buildenv.2020.107242

change in terms of the average results of different laboratories in the $1^{\text {st }}$ and the $2^{\text {nd }}$ rounds. It should be mentioned that in the $1^{\text {st }}$ round both Lab G and Lab I used automatic capillary absorption setups, while for all other cases in both rounds the manual method was adopted. To analyze the impact of different setups, we conducted Duncan's multiple range test [40], comparing the average capillary absorption coefficients of $\mathrm{Lab} \mathrm{G}$ in the $1^{\text {st }}$ and the $2^{\text {nd }}$ rounds, Lab $\mathrm{I}$ in the $1^{\text {st }}$ round and all other laboratories in the $1^{\text {st }}$ round. Results show that all these average values are not statistically different $(\mathrm{p}=0.074)$. This means both automatic and manual measurements could produce similar results, agreeing with an earlier study [45].

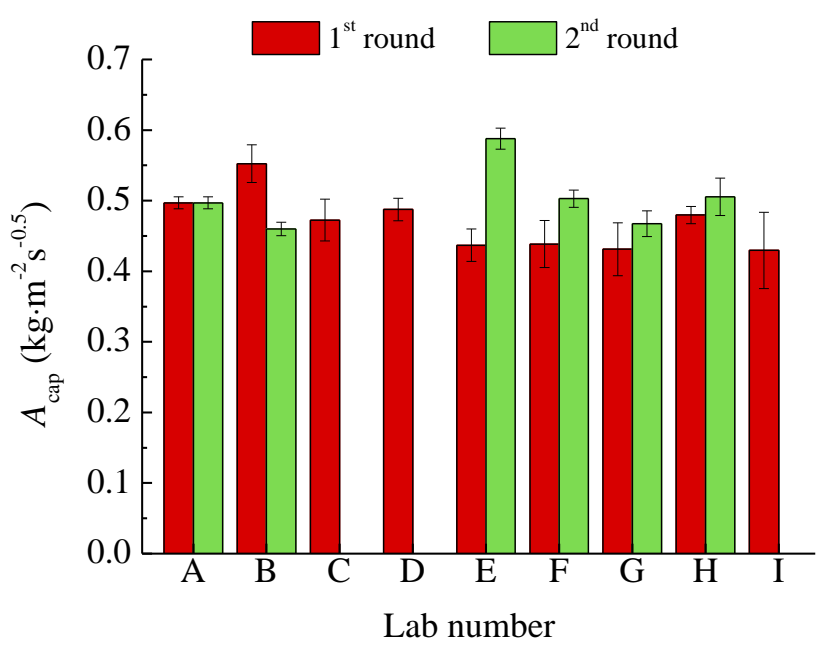

a) The capillary absorption coefficient

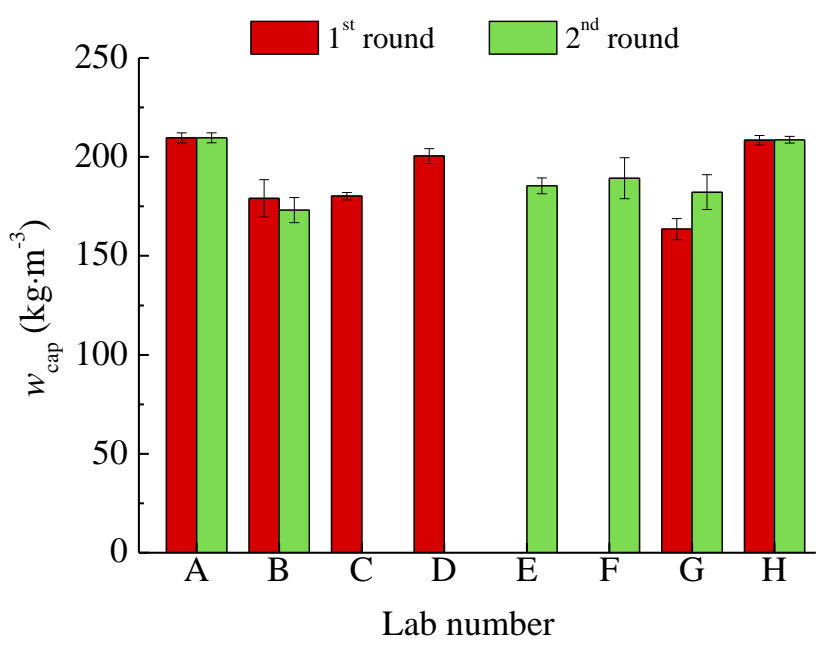

b) The capillary moisture content

Fig. 9 Results of the capillary absorption test $\left(A_{\text {cap }}\right.$ corrected to $20^{\circ} \mathrm{C}$ )

The reproducibility errors are illustrated in Fig. 10. It is clear that compared with the EC HAMSTAD project, the inter-laboratory errors for measuring the capillary absorption coefficient in this round robin has been reduced obviously, even without a common protocol. Resultantly, in this campaign the reproducibility errors with and without a common protocol are not very different, always staying within $7 \%-10 \%$, acceptable in most circumstances. It can thus be concluded that the capillary absorption test has become dependable now, and that further details through a more specific common protocol are not necessary anymore.

To have further insight, Table 4 summarizes the key information - sample size and sealing method - of the capillary absorption tests in the $1^{\text {st }}$ round. In comparison, all laboratories turned to $8 \mathrm{~cm} \times 4 \mathrm{~cm} \times 12 \mathrm{~cm}$ as the sample size and used plastic film or aluminum foil for sealing in the $2^{\text {nd }}$ round, as required by the common protocol. From such information, several interesting phenomena can be observed. Firstly, Labs C, E and F used the raw brick as the sample in the $1^{\text {st }}$ round, and their results (both the capillary absorption coefficient and the capillary moisture content) are among the smallest. One possibility is that the brick surface has slightly different characteristics than the core due to the manufacturing process. Another potential reason is that due to the coarseness and irregularity of the raw brick, the sample size was overestimated, leading to underestimated results. As is reflected in Fig. 9 a), once switched to the core material in the $2^{\text {nd }}$ round, the capillary absorption coefficients from Labs E and F increased immediately. Secondly, varied sample sizes - especially the height - were chosen by respective laboratories in the $1^{\text {st }}$ round. The results are however not highly different, even when compared with the $2^{\text {nd }}$ round experiments with the same sample size. This agrees with an earlier 
study, stating that the sample size has a limited impact on the capillary absorption test [21]. Last but not least, the sealing methods used by different laboratories in the $1^{\text {st }}$ round showed a great variety, and no significant influence can be observed. However, the cases with penetrating sealants (e.g. Labs E, F and I) generally produced lower capillary absorption coefficients, indicating that the potential sealant penetration may reduce the cross-sectional area. It is therefore more advisable to choose films for the sealing, as suggested in ref. [21]. Interestingly, Lab $\mathrm{H}$ did not seal samples in the $1^{\text {st }}$ round but still obtained consistent results with other laboratories. This is because the aim of sealing is to prevent evaporation during the capillary absorption process. If a sample absorbs much moisture within a short period of time (such as the brick investigated in this study), then the evaporation from its surfaces only exerts a limited impact and the sealing is hence no longer indispensable. Since it is difficult to define "much" and "short period" quantitatively, it may be more advisable to always seal samples with films.

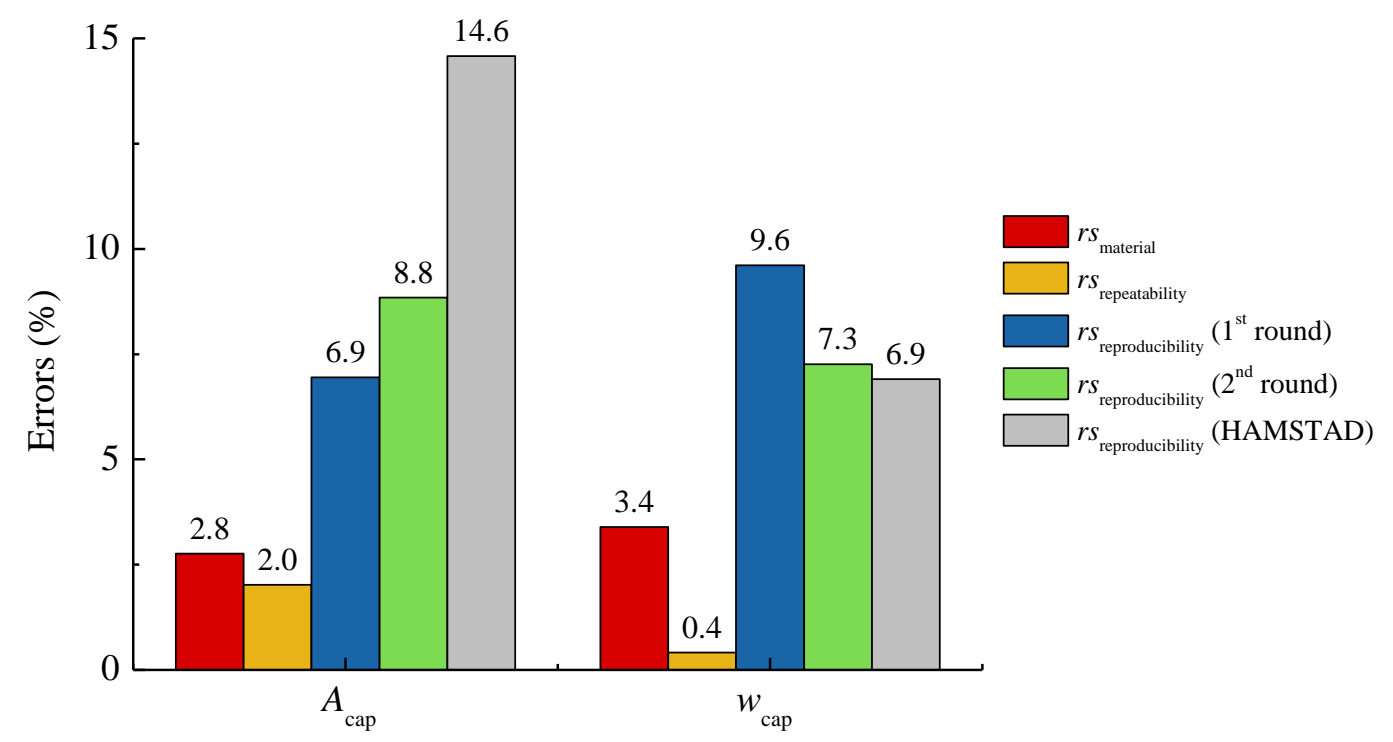

Fig. 10 Experimental errors of the round robin capillary absorption test

Table 4 Key information of the $1^{\text {st }}$ round capillary absorption tests for respective laboratories

\begin{tabular}{cccc}
\hline \multirow{2}{*}{ Lab No. } & \multicolumn{2}{c}{ Sample size $(\mathrm{cm})$} & Sealing method \\
\hline A & Surface & Height & Non-adhesive plastic film \\
B & $8 \times 4$ & 12 & Non-adhesive plastic film \\
C & $10 \times 5^{*}$ & 12 & Epoxy \\
D & $8 \times 4$ & 21 & Plastic film \\
E & $10 \times 5^{*}$ & 12 & Paint \\
F & $10 \times 5^{*}$ & 21 & Silicone paste \\
G & $4 \times 3$ & 21 & aluminium foil \\
H & $8 \times 4$ & 5 & No sealing \\
I & $4 \times 4$ & 12 & Epoxy \\
\hline
\end{tabular}

* Raw bricks were used.

As a matter of fact, the capillary absorption process has been extensively studied in the past decades and most impact factors have been thoroughly investigated. However, there is one factor remaining 
Postprint: Feng C, et al. 2020. Hygric properties of porous building materials (VI): a round robin campaign. Building and Environment, 2020;185:107242.

doi: https://doi.org/10.1016/j.buildenv.2020.107242

controversial: time correction. During the manual measurement the sample must be taken out of the water basin for weighing periodically, and no consensus has been reached concerning whether to correct this time interval. Normally 5-10 points are determined for calculating the capillary absorption coefficient, and with practice each weighing could be limited to 15-20 s, producing a total time of 2-3 min without water contact at the bottom. Since capillary absorption tests normally take a couple of hours, time correction resultantly produces a larger capillary absorption coefficient by $2 \%-5 \%$ in most cases. This correction partly explains that Lab G obtained a slightly larger capillary absorption coefficient in the $2^{\text {nd }}$ round (the manual method with time correction was used) when compared with their $1^{\text {st }}$ round result (the automatic method was used, involving no time correction), and that Lab I reported the smallest capillary absorption coefficient in the $1^{\text {st }}$ round (also the automatic method was used). However, overall there has been no decisive evidence supporting or against time correction, calling for further study.

\subsection{Cup tests}

Fig. 11 illustrates the vapor diffusion resistance factors obtained from the cup tests. Compared with the vacuum saturation test and the capillary absorption test, the scatters of the cup test between different laboratories are conspicuously larger in the $1^{\text {st }}$ round. This trend can also be observed in the EC HAMSTAD project and other round robin campaigns. For our case, the smallest value bottoms at 6.0 (Lab F) while the largest value goes up to 25.8 ( $\mathrm{Lab} \mathrm{G}$ ), producing a factor 4.3 difference. This difference is too large to be solely attributed to the limited RH dependence of the resistance factor for the studied brick, and the inter-laboratory discrepancy should play the key role. In the $2^{\text {nd }}$ round, notable improvement can be observed, as the results generally display a closer distribution. However, Lab F strangely gave an even worse result, as its reported value decreased from 6.0 in the $1^{\text {st }}$ round to 4.2 in the $2^{\text {nd }}$ round at the same RH condition. One explanation is that both the air layer inside the cup and the masked edge of the sample were corrected in the $2^{\text {nd }}$ round but uncorrected in the $1^{\text {st }}$ round by Lab F. These corrections resultantly lead to a smaller resistance factor. Moreover, the sample thickness was reduced from $5 \mathrm{~cm}$ in the $1^{\text {st }}$ round to $3 \mathrm{~cm}$ in the $2^{\text {nd }}$ round for Lab F, making the influence of corrections more significant. Nevertheless, the large deviation of Lab F cannot be completely attributed to these reasons and a more profound factor must exist. One possibility is the sealing leakage, which typically causes underestimated resistance factors [46], especially for relatively non-permeable materials (as the ceramic brick in this campaign). For statistical analysis, the results of Lab $\mathrm{F}$ in the $2^{\text {nd }}$ round are hence excluded.

It should be noted that different laboratories performed the cup test in this campaign at slightly different RH settings. It is therefore impossible to conduct statistical analysis strictly at the same RH. However, the ceramic brick used in this campaign is very weak in hygroscopicity (its equilibrium moisture content at RH $85 \%$ in the desiccator test is less than $0.05 \% \mathrm{~kg} \cdot \mathrm{kg}^{-1}$ ). Thus, the liquid island effect should be limited, and it is reasonable to summarize the results into the dry cup group and the wet cup group, depending on whether the average RH in the test is below or above $50 \%$. The independent t-tests comparing the $1^{\text {st }}$ and the $2^{\text {nd }}$ rounds provide p-values of 0.573 and 0.776 for dry cup and wet cup respectively, showing that the lab-averaged vapor diffusion resistance factors had no statistical difference in both rounds.

The calculated reproducibility errors are illustrated in Fig. 12, in comparison with the EC HAMSTAD project. As is clearly reflected, the $1^{\text {st }}$ round results display almost the same reproducibility errors as in the EC HAMSTAD project, be it dry cup or wet cup, indicating limited progress. In our $2^{\text {nd }}$ round campaign with a common protocol, the reproducibility errors for the dry and wet cup tests 
drop significantly, reaching $10.3 \%$ and $14.0 \%$, respectively. This encouraging improvement demonstrates that with a common protocol and careful operation, it is possible for different laboratories to achieve relatively consistent cup test results. However, as revealed by the independent t-tests on all properties, it must be reiterated that the common protocol only reduces the scatters between different laboratories, while not affecting their average result.

One may doubt that it is the smaller number of participating labs in the $2^{\text {nd }}$ round that reduced the reproducibility errors. However, from the statistical perspective, a larger sample number usually leads to smaller scatters - such as the standard deviation. Consequently, more participating labs in the $1^{\text {st }}$ round should lead to smaller reproducibility errors. However, the opposite was true for the $2^{\text {nd }}$ round, proving that there was an important change - the common protocol - that reduced the inter-laboratory errors. This is clearly evidenced by Lab A, B, E and G, which were involved in both rounds. It can be intuitively observed from Fig. 11 that the discrepancies between these four labs were much smaller in the $2^{\text {nd }}$ round, confirming the contribution of the common protocol with the same participant number.

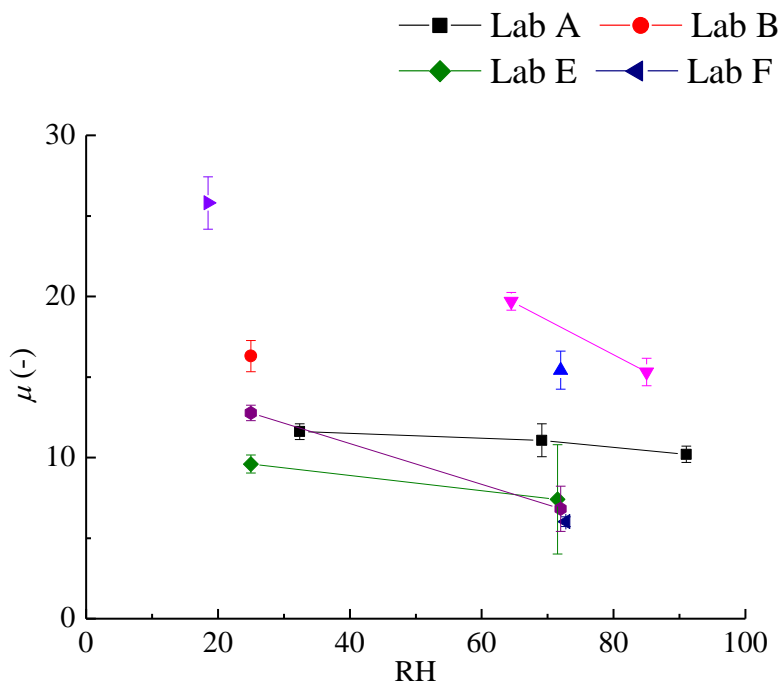

a) The $1^{\text {st }}$ round

Fig. 11 Results of the cup test

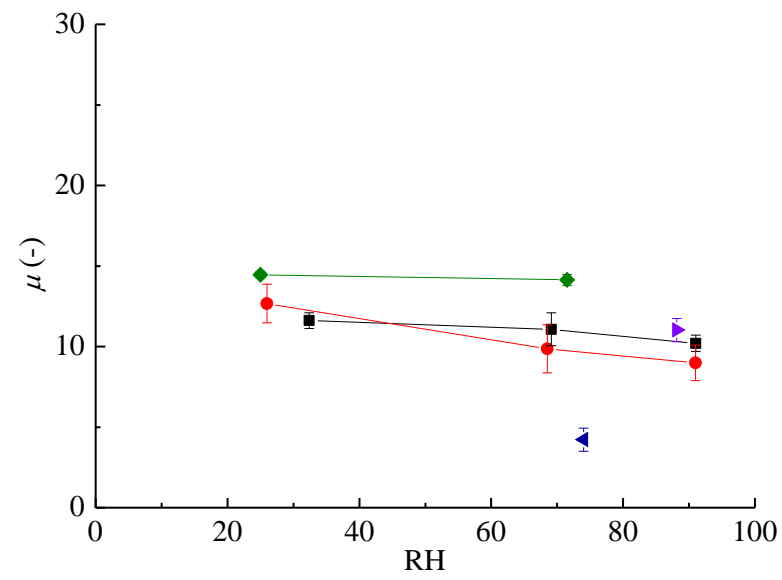

b) The $2^{\text {nd }}$ round

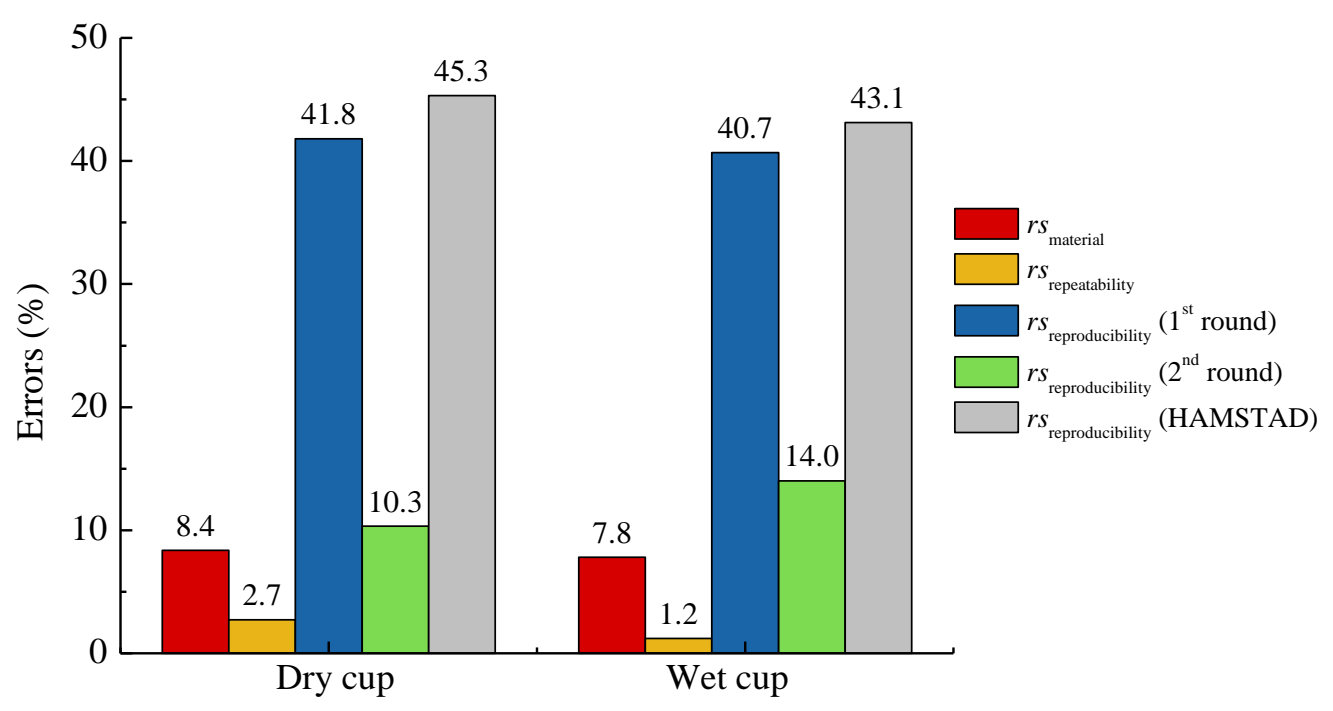

Fig. 12 Experimental errors of the round robin cup test 
Postprint: Feng C, et al. 2020. Hygric properties of porous building materials (VI): a round robin campaign. Building and Environment, 2020;185:107242.

doi: https://doi.org/10.1016/j.buildenv.2020.107242

\begin{tabular}{|c|c|c|c|c|c|c|}
\hline \multirow{2}{*}{ Lab No. } & \multicolumn{2}{|c|}{ Sample size $(\mathrm{cm})$} & \multirow{2}{*}{ Sealing method } & \multicolumn{3}{|c|}{ Correction for } \\
\hline & Surface & Thickness & & Surface resistance & Air layer in the cup & Masked edge \\
\hline A & Diameter $=8$ & 3 & Epoxy & No & Yes & No masked edge \\
\hline $\mathrm{B}$ & $10 \times 10$ & 1.7 & Paraffin & No & No & No masked edge \\
\hline $\mathrm{C}$ & Diameter $=7$ & 3.5 & Paraffin & No & No & No masked edge \\
\hline $\mathrm{D}$ & Diameter $=6.4$ & 2 & Tape & No & Yes & No masked edge \\
\hline $\mathrm{E}$ & $20 \times 20^{*}$ & 5 & Paraffin and tape & Yes & Yes & Yes \\
\hline $\mathrm{F}$ & Diameter $=8$ & 5 & Silicone paste & No & No & No \\
\hline G & $7 \times 7$ & 2.4 & Paint and paraffin & No & Yes & No masked edge \\
\hline I & Diameter $=9$ & 3 & Plasticine & No & No & Unreported \\
\hline
\end{tabular}

The cup test is a classic and widely adopted method to determine the vapor permeability. As revealed by other round robin campaigns (such as those listed in Table 1), it is one of the most difficult tests to obtain similar results in different laboratories. Various factors can exert possible impacts. It is therefore important to specify these details to reduce the discrepancies between different laboratories. Table 5 summarizes the key information - sample size, sealing method and correction - of the cup tests in the $1^{\text {st }}$ round. In comparison, all laboratories turned to a fixed thickness of $3 \mathrm{~cm}$ and similar surface areas in the $2^{\text {nd }}$ round. The air layer and the masked edge (if any) were corrected, and the air velocity was also increased to minimize the surface resistance in the $2^{\text {nd }}$ round.

Cup tests are normally performed around standard atmospheric pressure in different laboratories, so the limited air pressure fluctuation is unlikely to cause a large discrepancy [23, 47]. It has also been shown - both theoretically and experimentally - that temperature's influence is not strong [37], so the normal experimental temperature - usually around $20-25^{\circ} \mathrm{C}$ - is unlikely to be a main source of error. Moreover, the sample's surface area does not have a significant impact [23, 47], as also reflected in Table 5. As a result, these factors are not very strictly prescribed in the common protocol.

In addition to these weak impacts, three other factors are worth special attention. The first one is sample thickness, which should be evaluated together with the correction for the air layer inside the cup and the surface resistance outside the samples. The $\mathrm{s}_{\mathrm{d}}$ value for the air layer and surface resistance normally amounts to $3-5 \mathrm{~cm}$ in total. If the sample's $\mathrm{S}_{d}$ value is too small, then the correction of the air layer and surface resistance becomes very important. For this reason, the ISO 12572 standard [35] requires the sample's $S_{d}$ value to be at least $10 \mathrm{~cm}$. Moreover, the air velocity above the surface should be high enough and the air layer in the cup should be as thin as possible. Combining Fig. 11 a) and Table 5, it can be generalized that those laboratories with a small sample thickness (Labs B, D and G) tended to have larger resistance factors in the $1^{\text {st }}$ round, in accordance with the aforementioned analysis.

The second important impact is sample sealing [22, 27, 46], which consists of the lateral coating of the sample and the fixing of the sample on the diffusion cup. If not handled properly, the lateral coating can cause sealant penetration deep into the sample, reducing the real cross-sectional area for vapor diffusion and finally leads to an overestimated resistance factor. On the contrary, imperfect sealing between the sample and the diffusion cup will lead to vapor leakage and resultantly an underestimation of the resistance factor. Obviously, the more impermeable the material is, the greater the impact of the sample sealing can be. Looking at Table 5, one can easily notice that Lab E combined two raw bricks for the test in the $1^{\text {st }}$ round, and the results were almost the smallest. This may result from the imperfect 
Postprint: Feng C, et al. 2020. Hygric properties of porous building materials (VI): a round robin campaign. Building and Environment, 2020;185:107242.

doi: https://doi.org/10.1016/j.buildenv.2020.107242

sealing between the two raw bricks. Once switched to the sample cut from a single brick, the results from Lab E increased to the average value.

The last crucial factor is humidity control $[25,46]$. In the cup test, desiccant and saturated salt solutions are most frequently used to create the desired RH inside and/or outside the cups. If the desiccant becomes wet or if the salt solution fails to remain saturated, the real RH will be higher than the assumed value. As a result, the vapor pressure gradient across the sample can be underestimated or overestimated, leading to deviating results. It is therefore important to handle the desiccant and saturated salt solutions very carefully.

In the $2^{\text {nd }}$ round of experiments, we imposed stringent requirements concerning the aforementioned important impacts. As demonstrated by the results, the agreement between different laboratories achieved significant improvement with the common protocol. It is therefore necessary to pay special attention to these factors while carrying out cup tests.

\section{Conclusions}

A round robin campaign aiming at the hygric properties of porous building materials has been launched. A ceramic brick was selected as the target material. The vacuum saturation test for the bulk density and open porosity, the capillary absorption test for the capillary absorption coefficient and capillary moisture content, and the cup test for the vapor permeability, were performed. Results from nine participating laboratories from different countries show that:

a. Different laboratories can obtain similar results from the vacuum saturation test and the capillary absorption test, even without a common protocol;

b. Compared with the EC HAMSTAD project, the inter-laboratory discrepancies for the capillary absorption coefficient in this round robin campaign are much smaller;

c. The state-of-the-art for the cup test remains frustrating. However, with a stringent common protocol prescribing important impact factors, it is possible to achieve relatively consistent cup test results between different laboratories;

d. A common protocol can possibly reduce the discrepancies between laboratories, but not the average result of all laboratories.

Finally, it should be kept in mind that although a common protocol may reduce inter-laboratory discrepancies, it does not necessarily represent the preferred or recommended procedures of the individual participating laboratories.

\section{References}

[1] Zhou X, Carmeliet J, Derome D. Influence of envelope properties on interior insulation solutions for masonry walls. Building and Environment. 2018;135:246-56.

[2] Zhou X, Carmeliet J, Derome D. Assessment of risk of freeze-thaw damage in internally insulated masonry in a changing climate. Building and Environment. 2020;175:106773.

[3] Feng C, Roels S, Janssen $\mathrm{H}$. Towards a more representative assessment of frost damage to porous building materials. Building and Environment. 2019;164:106343.

[4] Shi L, Zhang H, Li Z, Man X, Wu Y, Zheng C, et al. Analysis of moisture buffering effect of straw-based board in civil defence shelters by field measurements and numerical simulations. Building and Environment. 2018;143:366-77.

[5] Zhang H, Yoshino H, Hasegawa K, Liu J, Zhang W, Xuan H. Practical moisture buffering effect of three hygroscopic materials in real-world conditions. Energy and Buildings. 2017;139:214-23.

[6] Havinga L, Schellen H. Applying internal insulation in post-war prefab housing: Understanding and mitigating the 
Postprint: Feng C, et al. 2020. Hygric properties of porous building materials (VI): a round robin campaign. Building and Environment, 2020;185:107242.

doi: https://doi.org/10.1016/j.buildenv.2020.107242

hygrothermal risks. Building and Environment. 2018;144:631-47.

[7] Hens H. Modeling the heat, air, and moisture response of building envelopes: What material properties are needed, how trustful are the predictions. Journal of ASTM International. 2007;4:1-11.

[8] Woloszyn M, Rode C. IEA Annex 41: Whole Building Heat, Air, Moisture Response. Subtask 1: Modeling Principles and Common Exercises. 2008.

[9] Walle WVD, Claes S, Janssen H. Implementation and validation of a 3D image-based prediction model for the thermal conductivity of cellular and granular porous building blocks. Construction and Building Materials. 2018;182:427-40.

[10] Islahuddin M, Janssen H. Pore-Structure-Based Determination of Unsaturated Hygric Properties of Porous Materials. Transport in Porous Media. 2019;130:675-98.

[11] ASTM C518 - 17: Standard Test Method for Steady-State Heat Flux Measurements and Thermal Transmission Properties by Means of the Heat Flow Meter Apparatus. 2017.

[12] ISO 8301: 1991(E) Thermal insulation - Determination of steady-state thermal resistance and related properties Heat flow meter apparatus. 1991.

[13] Fredriksson M, Johansson P. A Method for Determination of Absorption Isotherms at High Relative Humidity Levels: Measurements on Lime-Silica Brick and Norway Spruce (Picea abies(L.) Karst.). Drying Technology. 2016;34:132-41.

[14] Fredriksson M, Thybring EE. On sorption hysteresis in wood: Separating hysteresis in cell wall water and capillary water in the full moisture range. PloS one. 2019;14:e0225111.

[15] Feng C, Janssen H. Hygric properties of porous building materials (IV): Semi-permeable membrane and psychrometer methods for measuring moisture storage curves. Building and Environment. 2019;152:39-49.

[16] ASTM D4404 - 18: Standard Test Method for Determination of Pore Volume and Pore Volume Distribution of Soil and Rock by Mercury Intrusion Porosimetry. 2018.

[17] Good RJ, Mikhail RS. The contact angle in mercury intrusion porosimetry. Powder Technology. 1981;29:53-62.

[18] Diamond S. Mercury porosimetry: an inappropriate method for the measurement of pore size distributions in cement-based materials. Cement and Concrete Research. 2000;30:1517-25.

[19] ISO 12571: 2013(E) Hygrothermal performance of building materials and products - Determination of hygroscopic sorption properties. 2013.

[20] Jerman M, Palomar I, Kočí V, Černý R. Thermal and hygric properties of biomaterials suitable for interior thermal insulation systems in historical and traditional buildings. Building and Environment. 2019;154:81-8.

[21] Feng C, Janssen H. Hygric properties of porous building materials (III): Impact factors and data processing methods of the capillary absorption test. Building and Environment. 2018;134:21-34.

[22] Feng C, Todorović J, Janssen $\mathrm{H}$. Impact of time and personnel on measurements of the hygric properties of building materials. Energy Procedia. 2017;132:291-6.

[23] Galbraith GH, McLean RC, Tao Z. Vapour permeability: Suitability and consistency of current test procedures. Building Services Engineering Research and Technology. 1993;14:67-70.

[24] Hansen $\mathrm{MH}$. Retention curves measured using pressure plate and pressure membrane apparatus: Description of method and interlaboratory comparison. Nordtest Technical Report 367. 1998.

[25] Time B, Uvsløkk S. Intercomparison on measurement of water vapour permeance. Nordtest - Project Agreement 1529-01. 2003.

[26] Adan O, Brocken H, Carmeliet J, Hens H, Roels S, Hagentoft CE. Determination of liquid water transfer properties of porous building materials and development of numerical assessment methods: introduction to the EC HAMSTAD project. Journal of Thermal Envelope and Building Science. 2004;27:253-60.

[27] Roels S, Talukdar P, James C, Simonson CJ. Reliability of material data measurements for hygroscopic buffering. International Journal of Heat and Mass Transfer. 2010;53:5355-63.

[28] Feng C, Janssen H, Feng $Y$, Meng Q. Hygric properties of porous building materials: Analysis of measurement 
Postprint: Feng C, et al. 2020. Hygric properties of porous building materials (VI): a round robin campaign. Building and Environment, 2020;185:107242.

doi: https://doi.org/10.1016/j.buildenv.2020.107242

repeatability and reproducibility. Building and Environment. 2015;85:160-72.

[29] https://www.vandersandengroup.com/bricks/en/brick-brickslip/robusta.

[30] Scarlett NVY, Madsen IC. Effect of microabsorption on the determination of amorphous content via powder X-ray diffraction. Powder Diffraction. 2018;33:26-37.

[31] Hamilton A, Hall C. Erratum: The mechanics of moisture-expansion cracking in fired-clay ceramics. Journal of Physics D: Applied Physics. 2013;46.

[32] ASTM C1585 - 13: Standard Test Method for Measurement of Rate of Absorption of Water by Hydraulic-Cement Concretes. 2013.

[33] ASTM C1794 - 15: Standard Test Methods for Determination of the Water Absorption Coefficient by Partial Immersion. 2015.

[34] ASTM E96 / E96M - 16: Standard Test Methods for Water Vapor Transmission of Materials. 2016.

[35] ISO 12572: 2016(E) Hygrothermal performance of building materials and products - Determination of water vapour transmission properties - Cup method. 2016.

[36] ISO 15148: 2002(E) Hygrothermal performance of building materials and products-determination of water absorption coefficient by partial immersion. 2002.

[37] Feng C, Janssen H. Hygric properties of porous building materials (II): Analysis of temperature influence. Building and Environment. 2016;99:107-18.

[38] Feng $\mathrm{C}$, Janssen $\mathrm{H}$. The influence of temperature on the capillary absorption coefficient-a confrontation of two recent papers in Building and Environment. Building and Environment. 2017;116:257-8.

[39] Ioannou I, Charalambous C, Hall C. The temperature variation of the water sorptivity of construction materials. Materials and Structures. 2017;50:208-19.

[40] Montgomery DC. Design and analysis of experiments. 5th Edition. New York: John Wiley \& Sons Inc; 2008.

[41] ISO 5725-2: 2019(E) Accuracy (trueness and precision) of measurement methods and results - Part 2: Basic method for the determination of repeatability and reproducibility of a standard measurement method. 2019.

[42] Hall C, Hamilton A. Beyond the sorptivity: definition, measurement and properties of the secondary sorptivity. Journal of Materials in Civil Engineering. 2018;30:04018049.

[43] Hall C, Hamilton A. Porosity-density relations in stone and brick materials. Materials and Structures. 2013;48:126571.

[44] Hall C, Hamilton A. Porosities of building limestones: using the solid density to assess data quality. Materials and Structures. 2016;49:3969-79.

[45] Bomberg M, Pazera M, Plagge R. Analysis of Selected Water Absorption Coefficient Measurements. Journal of Building Physics. 2005;28:227-43.

[46] Roels S. IEA Annex 41: Whole Building Heat, Air, Moisture Response. Subtask 2: Experimental Analysis of Moisture Buffering. 2008.

[47] Galbraith GH, McLean RC, Tao Z, Kang N. The comparability of water vapour permeability measurements. Building Research \& Information. 1992;20:364-72. 


\section{Appendix A: The common protocols for the round robin campaign}

This appendix gives the full descriptions of the common protocols imposed in the $2^{\text {nd }}$ round of the round robin campaign. General requirements, as well as the detailed experimental procedures and data processing methods, are explained for the vacuum saturation test, the capillary absorption test and the cup test.

\section{General requirements}

a) The ambient temperature for all measurements should be maintained within $20-25^{\circ} \mathrm{C}$, with a fluctuation smaller than $\pm 1^{\circ} \mathrm{C}$;

b) The surface $0.5-1 \mathrm{~cm}$ of the raw bricks should be removed for preparing samples, and at least 4 duplicates (without cracks observable by the naked eye) are required for each test;

c) Measure sample dimensions with calipers reading $0.01 \mathrm{~mm}$. For each dimension (length $L$, width $W$, thickness $I$ and diameter $D, \mathrm{~m}$ ), measure at least twice at different locations and take the average;

d) Samples should be dried in a ventilated oven at $70^{\circ} \mathrm{C}$ for at least 7 days. When 3 successive weighings (reading $0.01 \mathrm{~g}$, but preferably $0.001 \mathrm{~g}$ ) at intervals of at least 1 day show a relative fluctuation below $0.1 \%$, stop the drying process and take the average as the dry mass $m_{\mathrm{dry}}(\mathrm{kg})$.

\section{Vacuum saturation test}

Samples should have a size of $8 \mathrm{~cm} \times 4 \mathrm{~cm} \times 1 \mathrm{~cm}$ (can be cut from the capillary absorption samples after finishing that test).

\subsection{Experimental procedure}

a) Put dry samples in a vacuum container and evacuate the air inside. The air pressure in the container should stay below $3000 \mathrm{~Pa}$ for at least $4 \mathrm{~h}$;

b) Fill in distilled/deionized water into the container gradually. When the water level touches the bottom of samples, maintain a water level rise of around $5 \mathrm{~cm} / \mathrm{h}$ (or slower) until all samples are completely submerged;

c) Keep filling in water until the water level is $2 \mathrm{~cm}$ above the top of the sample. Then return the air pressure in the container to atmospheric pressure;

d) After at least $24 \mathrm{~h}$, weigh samples underwater and record the underwater mass $m_{\text {under }}(\mathrm{kg})$;

e) Take samples out of water and use a piece of moist paper/tissue/cloth to remove the liquid water on the surfaces. Then determine the wet mass $m_{\text {wet }}(\mathrm{kg})$ in the air immediately;

\subsection{Data processing}

f) The open porosity $\phi$ should be calculated by:

$$
\phi=\frac{m_{\text {wet }}-m_{\text {dry }}}{m_{\text {wet }}-m_{\text {under }}}
$$

g) The bulk density $\rho_{\text {bulk }}\left(\mathrm{kg} \cdot \mathrm{m}^{-3}\right)$ should be calculated by:

$$
\rho_{\text {bulk }}=\frac{m_{\text {dry }} \cdot \rho_{\text {water }}}{m_{\text {wet }}-m_{\text {under }}}
$$

where the water density $\left(\rho_{\text {water }}, \mathrm{kg} \cdot \mathrm{m}^{-3}\right)$ should be taken according to the water temperature. 


\section{Capillary absorption test}

Samples should have a size of $12 \mathrm{~cm} \times 8 \mathrm{~cm} \times 4 \mathrm{~cm}$, and one $8 \mathrm{~cm} \times 4 \mathrm{~cm}$ surface is used as the bottom to ensure the capillary absorption along the brick's longitudinal direction.

\subsection{Experimental procedure}

a) Wrap dry samples with either plastic film or aluminum foil on all surfaces except for the bottom. Leave 1-2 small holes at the top to allow air evacuation. To avoid capillary uptake between the sample and the wrap, the bottom $1 \mathrm{~cm}$ of the lateral sides should be left unwrapped. Note that for this test the dry mass includes the wrap;

b) Pour distilled/deionized water (pre-conditioned to the ambient temperature) into a shallow basin, where a metal/plastic sample holder with a limited contact surface is placed. The water level in the basin should be $3-5 \mathrm{~mm}$ above the top of the sample holder;

c) Put the wrapped sample (cooled down to ambient temperature) on the sample holder softly. The moment the sample touches water, start the timer (reading $1 \mathrm{~s}$ );

d) At time 2, 4, 7, 10, 15, 20, 25, 30, 40, 50, 60, 80, 100, 120, 150, 180 and 210 min, take the sample out of water and use a piece of moist paper/tissue/cloth to remove the liquid water adhered to the bottom. Immediately weigh the sample for $m(t)(\mathrm{kg})$ and put it back on the holder. The accumulated duration that the sample is not absorbing water from the basin (during the weighing process) should be corrected in the time $t(\mathrm{~s})$;

\subsection{Data processing}

e) Plot $\left[m(t)-m_{\mathrm{dry}}\right] /(W \cdot I)$ against $t^{0.5}$ and distinguish the $1^{\text {st }}$ and $2^{\text {nd }}$ stages of the capillary absorption process. There may be 1-2 points in the transition zone between the $1^{\text {st }}$ and $2^{\text {nd }}$ stages. Discard them;

f) Fit the data points in the $1^{\text {st }}$ stage with the following linear equation:

$$
\frac{m(t)-m_{\mathrm{dry}}}{W \cdot I}=A_{\mathrm{cap}} \cdot t^{0.5}+c
$$

where the slope is defined as the capillary absorption coefficient $\left(A_{\text {cap }}, \mathrm{kg} \cdot \mathrm{m}^{-2} \mathrm{~s}^{-0.5}\right)$;

g) Fit the data points in the $2^{\text {nd }}$ stage linearly, and calculate its cross point with the fitted straight line for the $1^{\text {st }}$ stage. The capillary moisture content $\left(w_{\text {cap }}, \mathrm{kg} \cdot \mathrm{m}^{-3}\right)$ should be calculated according to the following equation:

$$
W_{\text {cap }}=\left.\frac{m(t)-m_{\mathrm{dry}}}{L \cdot W \cdot I}\right|_{\text {cross point }}
$$

\section{Cup test}

Samples should have a thickness of $3 \mathrm{~cm}$. If round samples are used, the diameter should be $8-10$ $\mathrm{cm}$. For square samples $8-10 \mathrm{~cm}$ is required for the side length. The test should be carried out along the brick's thickness direction.

\subsection{Experimental procedure}

a) Seal the sample on the opening of the diffusion cup. The sealant can be epoxy, paraffin or other vapor-tight methods. While sealing, try to minimize the penetration of the sealant into the sample;

b) Put diffusion cups with sealed samples in a chamber where the relative humidity is controlled. Ensure an air velocity of at least $1 \mathrm{~m} \cdot \mathrm{s}^{-1}$ above the sample surface;

c) Inside the diffusion cup, humidity should be controlled by either saturated salt solutions or desiccant, while this can be achieved by saturated salt solution, HVAC system or other reliable methods outside the diffusion cup. Choose between the following two options in Table A1 (the $1^{\text {st }}$ 
Postprint: Feng C, et al. 2020. Hygric properties of porous building materials (VI): a round robin campaign. Building and Environment, 2020;185:107242.

is recommended):

Table A1 RH conditions for the cup test

\begin{tabular}{cccc}
\hline RH options & RH settings & Lower $\mathrm{RH}(\%)$ & Higher $\mathrm{RH}(\%)$ \\
\hline \multirow{4}{*}{$1^{\text {st }}$} & Dry & 0 or $11($ desiccant or $\mathrm{LiCl})$ & $54\left(\mathrm{Mg}\left(\mathrm{NO}_{3}\right)_{2}\right)$ \\
& Intermediate & $54\left(\mathrm{Mg}\left(\mathrm{NO}_{3}\right)_{2}\right)$ & $84(\mathrm{KCl})$ \\
& Wet & $84(\mathrm{KCl})$ & $94\left(\mathrm{KNO}_{3}\right)$ or $97\left(\mathrm{~K}_{2} \mathrm{SO}_{4}\right)$ \\
\hline \multirow{2}{*}{$2^{\text {nd }}$} & Dry & 0 or $11($ desiccant or $\mathrm{LiCl})$ & $54\left(\mathrm{Mg}\left(\mathrm{NO}_{3}\right)_{2}\right)$ \\
& Wet & $54\left(\mathrm{Mg}\left(\mathrm{NO}_{3}\right)_{2}\right)$ & $94\left(\mathrm{KNO}_{3}\right)$ or $97\left(\mathrm{~K}_{2} \mathrm{SO}_{4}\right)$ \\
\hline
\end{tabular}

d) After an initial period of 5-7 days for reaching steady-state, start weighing the diffusion cups for $m(t)$ (to $0.1 \mathrm{~g}$, preferably to $0.01 \mathrm{~g}$ ) every 2-4 days, until 7 successive weighings give excellent linear fitting results $\left(\mathrm{R}^{2}>0.99\right)$. The time should be recorded to the single minute;

e) Measure/estimate the thickness of the air layer $\left(I_{\text {air }}, \mathrm{m}\right)$ in the diffusion cup between the lower surface of the sample and the upper surface of the saturated solution (or desiccant) to $1 \mathrm{~mm}$;

\subsection{Data processing}

f) Fit the mass of the diffusion cup $m(t)$ against the time $t$ linearly. The slope should be denoted as $\dot{G}$ for the vapor flow rate $\left(\mathrm{kg} \cdot \mathrm{s}^{-1}\right)$;

g) Calculate the vapor flux $\left(\dot{g}, \mathrm{~kg} \cdot \mathrm{m}^{-2} \mathrm{~s}^{-1}\right)$ by:

$$
\dot{g}=\frac{\dot{G}}{A}
$$

where $A$ is the sample's cross-sectional area $\left(\mathrm{m}^{2}\right)$. In case a masked edge of the sample exists, the vapor flux should be corrected according to the ISO 12572 standard [35];

h) Calculate the total vapor diffusion resistance $R_{\text {total }}\left(\mathrm{m}^{2} \mathrm{sPa} \cdot \mathrm{kg}^{-1}\right)$ by:

$$
R_{\text {total }}=\frac{\Delta p_{\mathrm{v}}}{\dot{g}}
$$

where $\triangle p_{\mathrm{v}}(\mathrm{Pa})$ is the vapor pressure difference in and outside the diffusion cup, obtained based on the ambient temperature and the RH conditions;

i) Calculate the resistance of the air layer inside the diffusion cup $R_{\text {air }}\left(\mathrm{m}^{2} \mathrm{sPa} \cdot \mathrm{kg}^{-1}\right)$ by:

$$
R_{\text {air }}=\frac{I_{\text {air }}}{\delta_{\text {air }}}
$$

where $\delta_{\text {air }}$ is the vapor permeability of stagnant air. At $20-25^{\circ} \mathrm{C}$, its value can be taken as $2 \times 10^{-10}$ $\mathrm{kg} \cdot \mathrm{m}^{-1} \mathrm{~s}^{-1} \mathrm{~Pa}^{-1}$

j) Calculate the vapor diffusion resistance of the sample $R_{\text {sample }}\left(\mathrm{m}^{2} \mathrm{sPa} \cdot \mathrm{kg}^{-1}\right)$ by:

$$
R_{\text {sample }}=R_{\text {total }}-R_{\text {air }}
$$

k) Calculate the vapor permeability $\delta_{\text {sample }}\left(\mathrm{kg} \cdot \mathrm{m}^{-1} \mathrm{~s}^{-1} \mathrm{~Pa}^{-1}\right)$ and resistance factor $\mu$ of the sample by:

$$
\begin{gathered}
\delta_{\text {sample }}=\frac{I}{R_{\text {sample }}} \\
\mu=\frac{\delta_{\text {air }}}{\delta_{\text {sample }}}
\end{gathered}
$$

1) Calculate $\mu$ at different RH settings, and express the results against the average RH in and outside the diffusion cup. 


\section{Appendix B: Experimental results from the round robin campaign}

This appendix provides detailed experimental results from the round robin campaign, as summarized in Table A2 Table A4.

Table A2 Results of the vacuum saturation tests

\begin{tabular}{|c|c|c|c|c|c|c|c|c|c|c|}
\hline Property & $\mathrm{Lab}$ & Round & Temp. $\left({ }^{\circ} \mathrm{C}\right)$ & \multicolumn{6}{|c|}{ Results } & \multirow{2}{*}{$\begin{array}{c}\text { Average* } \\
1880 \text { (2) }\end{array}$} \\
\hline \multirow{12}{*}{$\begin{array}{c}\rho_{\text {bulk }} \\
\left(\mathrm{kg} \cdot \mathrm{m}^{-3}\right)\end{array}$} & \multirow{2}{*}{ A } & $1^{\text {st }}$ & 19.9 & 1879 & 1880 & 1878 & 1880 & 1884 & & \\
\hline & & $2^{\text {nd }}$ & 19.9 & 1879 & 1880 & 1878 & 1880 & 1884 & & $1880(2)$ \\
\hline & \multirow{2}{*}{ B } & $1^{\text {st }}$ & Unreported & 1909 & 1903 & 1912 & 1909 & 1903 & & $1907(4)$ \\
\hline & & $2^{\text {nd }}$ & 21.4 & 1880 & 1885 & 1856 & 1902 & 1902 & 1899 & $1887(18)$ \\
\hline & \multirow{2}{*}{$\mathrm{C}$} & $1^{\text {st }}$ & 23 & 1874 & 1931 & 1935 & & & & $1913(34)$ \\
\hline & & $2^{\text {nd }}$ & & & & & & & & \\
\hline & \multirow{2}{*}{ D } & $1^{\text {st }}$ & Unreported & 1907 & 1884 & 1898 & 1903 & 1879 & 1875 & $1891(13)$ \\
\hline & & $2^{\text {nd }}$ & & & & & & & & \\
\hline & \multirow{2}{*}{$\mathrm{F}$} & $1^{\text {st }}$ & & & & & & & & \\
\hline & & $2^{\text {nd }}$ & 23 & 1778 & 1818 & 1837 & 1794 & & & $1807(26)$ \\
\hline & \multirow{2}{*}{$\mathrm{H}$} & $1^{\text {st }}$ & Unreported & 1856 & 1854 & 1853 & 1848 & 1859 & 1850 & $1853(4)$ \\
\hline & & $2^{\text {nd }}$ & 25 & 1862 & 1853 & 1859 & 1853 & & & $1857(5)$ \\
\hline \multirow{12}{*}{$\begin{array}{c}\phi \\
(\%)\end{array}$} & \multirow{2}{*}{ A } & $1^{\text {st }}$ & 19.9 & 31.7 & 31.8 & 31.7 & 31.9 & 31.6 & & $31.7(0.1)$ \\
\hline & & $2^{\text {nd }}$ & 19.9 & 31.7 & 31.8 & 31.7 & 31.9 & 31.6 & & $31.7(0.1)$ \\
\hline & \multirow{2}{*}{ B } & $1^{\text {st }}$ & Unreported & 28.5 & 28.7 & 29.0 & 28.7 & 28.9 & & $28.8(0.2)$ \\
\hline & & $2^{\text {nd }}$ & 21.4 & 27.5 & 27.4 & 29.2 & 28.1 & 27.6 & 28.0 & $27.9(0.7)$ \\
\hline & \multirow{2}{*}{$\mathrm{C}$} & $1^{\text {st }}$ & 23 & 32.0 & 32.8 & 33.0 & & & & $32.6(0.5)$ \\
\hline & & $2^{\text {nd }}$ & & & & & & & & \\
\hline & \multirow{2}{*}{$\mathrm{D}$} & $1^{\text {st }}$ & Unreported & 30.4 & 31.4 & 30.9 & 30.7 & 31.7 & 31.8 & $31.2(0.6)$ \\
\hline & & $2^{\text {nd }}$ & & & & & & & & \\
\hline & \multirow{2}{*}{$\mathrm{F}$} & $1^{\text {st }}$ & & & & & & & & \\
\hline & & $2^{\text {nd }}$ & 23 & 25.0 & 24.0 & 23.0 & 25.0 & & & $24.3(1.0)$ \\
\hline & \multirow{2}{*}{$\mathrm{H}$} & $1^{\text {st }}$ & Unreported & 32.7 & 32.5 & 32.2 & 32.6 & 32.7 & 32.5 & $32.5(0.2)$ \\
\hline & & $2^{\text {nd }}$ & 25 & 32.2 & 32.3 & 32.2 & 32.7 & & & $32.4(0.2)$ \\
\hline
\end{tabular}

* Data in parenthesis are standard deviations. 
Postprint: Feng C, et al. 2020. Hygric properties of porous building materials (VI): a round robin campaign. Building and Environment, 2020;185:107242.

doi: https://doi.org/10.1016/j.buildenv.2020.107242

Table A3 Results of the capillary absorption tests

\begin{tabular}{|c|c|c|c|c|c|c|c|c|c|c|}
\hline Property & Lab & Round & Temp. $\left({ }^{\circ} \mathrm{C}\right)$ & \multicolumn{6}{|c|}{ Results* } & \multirow{2}{*}{$\begin{array}{c}\text { Average }^{* * *} \\
0.497(0.009)\end{array}$} \\
\hline \multirow{18}{*}{$\begin{array}{c}A_{\text {cap }} \\
\left(\mathrm{kg} \cdot \mathrm{m}^{-2} \mathrm{~s}^{-0.5}\right)\end{array}$} & \multirow{2}{*}{ A } & $1^{\text {st }}$ & 20.1 & 0.487 & 0.500 & 0.508 & 0.491 & 0.502 & & \\
\hline & & $2^{\text {nd }}$ & 20.1 & 0.487 & 0.500 & 0.508 & 0.491 & 0.502 & & $0.497(0.009)$ \\
\hline & $\mathrm{P}$ & $1^{\text {st }}$ & 23 & 0.587 & 0.604 & 0.588 & 0.527 & 0.557 & 0.563 & $0.571(0.028)$ \\
\hline & $\mathrm{B}$ & $2^{\text {nd }}$ & 20.5 & 0.463 & 0.471 & $0.524^{* * *}$ & 0.455 & 0.451 & 0.473 & $0.462(0.010)$ \\
\hline & & $1^{\text {st }}$ & 23 & 0.49 & 0.53 & 0.48 & 0.44 & 0.48 & 0.51 & $0.488(0.031)$ \\
\hline & $\mathrm{C}$ & $2^{\text {nd }}$ & & & & & & & & \\
\hline & & $1^{\text {st }}$ & 19.8 & 0.505 & 0.477 & 0.478 & & & & $0.486(0.016)$ \\
\hline & D & $2^{\text {nd }}$ & & & & & & & & \\
\hline & $F$ & $1^{\mathrm{st}}$ & 23 & 0.491 & 0.449 & 0.452 & 0.433 & 0.433 & & $0.452(0.024)$ \\
\hline & $\mathrm{E}$ & $2^{\text {nd }}$ & 23 & 0.600 & 0.601 & 0.610 & 0.594 & 0.633 & & $0.608(0.015)$ \\
\hline & $F$ & $1^{\text {st }}$ & 20 & 0.456 & 0.460 & 0.400 & & & & $0.439(0.033)$ \\
\hline & $F$ & $2^{\text {nd }}$ & 23 & 0.536 & 0.506 & 0.521 & 0.516 & & & $0.520(0.013)$ \\
\hline & $G$ & $1^{\text {st }}$ & 23 & 0.438 & 0.461 & 0.401 & 0.418 & 0.443 & 0.513 & $0.446(0.039)$ \\
\hline & $U$ & $2^{\text {nd }}$ & 23 & 0.459 & 0.495 & 0.478 & 0.500 & & & $0.483(0.019)$ \\
\hline & $H$ & $1^{\text {st }}$ & 25 & 0.500 & 0.508 & 0.524 & 0.494 & & & $0.507(0.013)$ \\
\hline & H & $2^{\text {nd }}$ & 25 & 0.513 & 0.569 & 0.510 & 0.543 & & & $0.534(0.028)$ \\
\hline & I & $1^{\text {st }}$ & Unreported & 0.373 & 0.443 & 0.490 & 0.468 & $0.298^{* * *}$ & 0.374 & $0.430(0.054)$ \\
\hline & 1 & $2^{\text {nd }}$ & & & & & & & & \\
\hline \multirow{16}{*}{$\begin{array}{c}w_{\text {cap }} \\
\left(\mathrm{kg} \cdot \mathrm{m}^{-3}\right)\end{array}$} & \multirow{2}{*}{ A } & $1^{\text {st }}$ & 20.1 & 209.5 & 208.1 & 206.4 & 212.1 & 212.1 & & $209.6(2.5)$ \\
\hline & & $2^{\text {nd }}$ & 20.1 & 209.5 & 208.1 & 206.4 & 212.1 & 212.1 & & $209.6(2.5)$ \\
\hline & \multirow{2}{*}{ B } & $1^{\text {st }}$ & 23 & 192.1 & 172.6 & 175.1 & 169.6 & 189.9 & 174.8 & $179.0(9.5)$ \\
\hline & & $2^{\text {nd }}$ & 20.5 & 170.7 & 168.4 & 184.9 & 170.5 & 168.7 & 175.5 & $173.1(6.3)$ \\
\hline & \multirow{2}{*}{$\mathrm{C}$} & $1^{\text {st }}$ & 23 & 182.4 & 178.6 & 180.5 & 178.6 & 178.6 & 182.4 & $180.2(1.8)$ \\
\hline & & $2^{\text {nd }}$ & & & & & & & & \\
\hline & \multirow{2}{*}{$\mathrm{D}$} & $1^{\text {st }}$ & 19.8 & 204.4 & 197.0 & 199.8 & & & & $200.4(3.7)$ \\
\hline & & $2^{\text {nd }}$ & & & & & & & & \\
\hline & \multirow{2}{*}{$\mathrm{E}$} & $1^{\text {st }}$ & & & & & & & & \\
\hline & & $2^{\text {nd }}$ & 23 & 189.1 & 183.7 & 182.1 & 181.9 & 190.2 & & $185.4(4.0)$ \\
\hline & \multirow{2}{*}{$\mathrm{F}$} & $1^{\text {st }}$ & & & & & & & & \\
\hline & & $2^{\text {nd }}$ & 23 & 197 & 193 & 174 & 193 & & & $189.3(10.3)$ \\
\hline & \multirow{2}{*}{ G } & $1^{\text {st }}$ & 23 & 164.7 & 172.8 & 157.3 & 160.7 & 164.2 & 161.4 & $163.5(5.3)$ \\
\hline & & $2^{\text {nd }}$ & 23 & 169.8 & 184.3 & 184.1 & 190.5 & & & $182.2(8.8)$ \\
\hline & \multirow{2}{*}{$\mathrm{H}$} & $1^{\text {st }}$ & 25 & 209.4 & 204.9 & 210.7 & 208.6 & & & $208.4(2.5)$ \\
\hline & & $2^{\text {nd }}$ & 25 & 209.8 & 206.3 & 208.4 & 210.2 & & & $208.7(1.8)$ \\
\hline
\end{tabular}

\footnotetext{
* Original values, temperature dependence uncorrected;
}

** Data in parenthesis are standard deviations;

*** Outlier, discarded. 


\section{Table A4 Results of the cup tests}

\begin{tabular}{|c|c|c|c|c|c|c|c|c|c|c|}
\hline Round & $\mathrm{Lab}$ & Temp. $\left({ }^{\circ} \mathrm{C}\right)$ & RH (\%) & \multicolumn{6}{|c|}{$\mu$} & \multirow{2}{*}{$\begin{array}{l}\text { Average* } \\
11.6(0.5)\end{array}$} \\
\hline \multirow{13}{*}{$1^{\text {st }}$} & \multirow{3}{*}{ A } & \multirow{3}{*}{23.1} & $11.3-53.5$ & 11.3 & 11.3 & 12.3 & 11.6 & & & \\
\hline & & & $53.5-84.7$ & 10.6 & 10.5 & 10.6 & 12.6 & & & $11.1(1.0)$ \\
\hline & & & $84.7-97.4$ & 9.6 & 10.1 & 10.7 & 10.4 & & & $10.2(0.5)$ \\
\hline & $\mathrm{B}$ & 23 & $0-50$ & 17.1 & 17.1 & $22.1^{* *}$ & 15.8 & 15.2 & & $16.3(1.0)$ \\
\hline & $\mathrm{C}$ & 23 & $50-94$ & 15.5 & 15.0 & 13.3 & 16.5 & 16.5 & 15.6 & $15.4(1.2)$ \\
\hline & $\mathrm{D}$ & & $54-75$ & 20.3 & $25.9^{* *}$ & 19.0 & 19.8 & 19.7 & & $19.7(0.5)$ \\
\hline & D & 19.8 & $75-95$ & 14.4 & $9.4^{* *}$ & 16.5 & 15.2 & 15.1 & & $15.3(0.8)$ \\
\hline & $\mathrm{F}$ & 23 & $0-50$ & 10.0 & 9.2 & & & & & $9.6(0.6)$ \\
\hline & $\mathrm{L}$ & 20 & $50-93$ & 5.0 & 9.8 & & & & & $7.4(3.4)$ \\
\hline & $\mathrm{F}$ & 23 & $50-95.5$ & 6.2 & 6.4 & 5.9 & 5.6 & 6.0 & & $6.0(0.3)$ \\
\hline & G & 22.7 & $1-36$ & 23.8 & 25.2 & 28.3 & 27.1 & 25.1 & 25.2 & $25.8(1.6)$ \\
\hline & $\mathrm{I}$ & 23 & $0-50$ & 13.2 & 13.2 & 12.5 & 12.3 & & & $12.8(0.5)$ \\
\hline & 1 & 20 & $50-94$ & 6.3 & 7.6 & 8.3 & 5.2 & & & $6.8(1.4)$ \\
\hline & & & $11.3-53.5$ & 11.3 & 11.3 & 12.3 & 11.6 & & & $11.6(0.5)$ \\
\hline & A & 23.1 & $53.5-84.7$ & 10.6 & 10.5 & 10.6 & 12.6 & & & $11.1(1.0)$ \\
\hline & & & $84.7-97.4$ & 9.6 & 10.1 & 10.7 & 10.4 & & & $10.2(0.5)$ \\
\hline & & & $0-52$ & 12.5 & 13.0 & 10.8 & 14.0 & 12.0 & 13.7 & $12.7(1.2)$ \\
\hline nd & B & 20 & $52-85$ & 12.1 & 11.0 & 10.0 & 8.7 & 8.3 & 9.1 & $9.9(1.5)$ \\
\hline $2^{2 u}$ & & & $85-97$ & 10.1 & 8.7 & 10.2 & 9.5 & 7.8 & 7.7 & $9.0(1.1)$ \\
\hline & $F$ & 23 & $0-50$ & 14.7 & 14.4 & 14.3 & & & & $14.5(0.2)$ \\
\hline & $\mathrm{L}$ & $2 J$ & $50-93$ & 13.8 & 14.1 & 14.5 & & & & $14.1(0.4)$ \\
\hline & $\mathrm{F}$ & 23 & 54-94 & 3.5 & 5.1 & 4.7 & 3.5 & 4.3 & & $4.2(0.7)$ \\
\hline & G & 23 & $80.3-96$ & 10.1 & 11.2 & 11.8 & 11.1 & & & $11.0(0.7)$ \\
\hline
\end{tabular}

* Data in parenthesis are standard deviations;

** Outlier, discarded. 